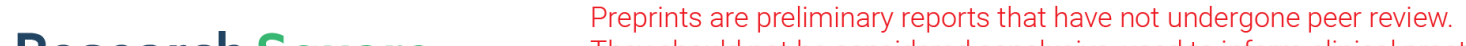 They should not be considered conclusive, used to inform clinical practice, or referenced by the media as validated information. \\ Egg White/Polyvinyl Alcohol/Clay \\ Bionanocomposite Hydrogel Adsorbents for Dye Removal
}

\section{Homa Khadivi}

Urmia University of Technology

Mohammad Sirousazar ( $\sim$ m.sirousazar@uut.ac.ir)

Urmia University of Technology https://orcid.org/0000-0002-2146-0351

Vahid Abbasi-Chianeh

Urmia University of Technology

Elham Jalilnejad

Urmia University of Technology

\section{Research Article}

Keywords: Adsorption, Egg white, Polyvinyl alcohol, Montmorillonite, Methylene blue, Taguchi method

Posted Date: December 13th, 2021

DOI: https://doi.org/10.21203/rs.3.rs-1117453/v1

License: (a) (i) This work is licensed under a Creative Commons Attribution 4.0 International License. Read Full License

Version of Record: A version of this preprint was published at Journal of Polymers and the Environment on March 22nd, 2022. See the published version at https://doi.org/10.1007/s10924-022-02430-4. 


\title{
Egg White/Polyvinyl Alcohol/Clay Bionanocomposite Hydrogel Adsorbents for Dye Removal
}

\author{
Homa Khadivi ${ }^{1}$, Mohammad Sirousazar ${ }^{1, *}$, Vahid Abbasi-Chianeh ${ }^{2}$, \\ Elham Jalilnejad ${ }^{1}$
}

\footnotetext{
${ }^{1}$ Faculty of Chemical Engineering, Urmia University of Technology, Urmia, Iran

${ }^{2}$ Materials Engineering Group, Urmia University of Technology, Urmia, Iran
}

${ }^{*}$ Corresponding author.

Email address: m.sirousazar@uut.ac.ir (M. Sirousazar) 


\begin{abstract}
In the current study, bionanocomposite hydrogels based on egg white and polyvinyl alcohol loaded with 0,4 and $8 \mathrm{wt} . \%$ of montmorillonite clay were prepared and utilized as effective adsorbents for removing the methylene blue from aqueous solutions. The structural characteristics of the prepared adsorbents were studied and the gel content, the influence of the $\mathrm{pH}$ of the medium on swelling kinetics and the methylene blue diffusion coefficient in the adsorbents were investigated. It was found that the swelling ratio and diffusion coefficient of bionanocomposite hydrogel adsorbents increased either with increasing the $\mathrm{pH}$ of the medium or decreasing the loading level of montmorillonite and gel contact had a direct dependency on the montmorillonite content. Taguchi method was utilized to determine the effects of main factors on the batch adsorption process, including the montmorillonite loading level in adsorbent, $\mathrm{pH}$ of the solution and dye initial concentration in adsorption solution. The optimum adsorption conditions by the Taguchi method were determined as montmorillonite loading level of $8 \mathrm{wt} \%$, $\mathrm{pH}$ of 9 and methylene blue initial concentration of $5 \mathrm{mg} / \mathrm{L}$. The experimental adsorption results were fitted to the various isotherms and kinetic models. It was shown that intra-particle diffusion was the best model for elucidating adsorbents' behavior in methylene blue removal. It was finally deduced that the prepared bionanocomposite hydrogel adsorbents could be recognized as effective eco-friendly adsorbents for removing the cationic dyes from wastewaters.
\end{abstract}

Keywords: Adsorption, Egg white, Polyvinyl alcohol, Montmorillonite, Methylene blue, Taguchi method 


\section{Introduction}

Water is considered a vital requirement for the sustainability of human life and other living beings and it plays an indispensable role in the proper functioning of the earth's ecosystems [1, 2]. However, over the past several decades, water resources have been facing unprecedented challenges. The industrialization of communities has resulted in pollution of the natural water resources with organic and inorganic pollutants [1,3]. Industrial wastewaters containing synthetic dyes, lead to intense contamination of the surface or ground waters in the vicinity of the industrial complexes [4]. Dyes are mainly resistant to degradation because of their complicated chemical structures and are usually stable under different conditions. Therefore, their discharges into the hydrosphere possess dramatic damages to the ecosystem $[5,6]$. Thus, removing dye molecules before the discharge of the effluents into water sources is a major environmental concern and a challenge [5]. Methylene blue (MB) is a common cationic dye utilized for the dyeing of various materials like wool and cotton. Even a small amount of this dye is toxic due to its complex aromatic structure and can cause various diseases and serious environmental problems [4].

A wide range of biological, chemical, and physical techniques have been introduced during the past years to treat dyeing wastewater [3]. The biological treatment includes anaerobic and aerobic degradation processes, whereas chemical methods include photolysis and photocatalytic and physical techniques, e.g. electrokinetic coagulation, membrane filtration, ion exchange and adsorption [7]. Among the traditional techniques used for removing dyes from effluents, adsorption has been reported as an efficient method due to its low operational cost, simple design and high efficiency $[3,7]$. The performance of the adsorption process is directly related to the nature and characteristics of the adsorbent material chosen for the dye removal [8]. For effective 
removal of dyes, an adsorbent should meet specific criteria, such as readily availability, simple preparation process, non-toxicity and reusability [9]. Nowadays, the interest of researchers is focused on utilizing natural biocompatible materials as eco-friendly adsorbents to prevent damaging the environment while treating water pollutants.

Egg white $(\mathrm{EW})$ is a cheap and abundant source of proteins, e.g. ovalbumin, lysozyme, conalbumin, ovomucin and ovomucoid, which has the required properties to be used as a biosorbent material in the dye adsorption process. It is simply degraded in the environment and does not lead to environmental pollution $[9,10]$. However, it is impossible to prepare a proper adsorbent based on EW due to its high solubility in aqueous solutions, either in fresh or dried forms. Therefore, special methods, such as crosslinking of EW and preparation of hydrogel-like EW-based materials, are required to prepare biocompatible adsorbents based on EW. For example, Oymak and Bagda recently used crosslinked EW with acrylamide to adsorb indigo carmine as a toxic dye [9]. They also obtained the optimal conditions of the experimental parameters (i.e., $\mathrm{pH}$ of the solution, dye initial concentration and adsorption time) to achieve high removal efficiency of the studied dye by EW-based adsorbent.

Hydrogels, as hydrophilic crosslinked polymeric materials, have also been utilized as functional adsorbents in the dye removal processes. Hydrogels consist of hydrophilic flexible polymeric networks which can absorb a large volume of water and swell but do not dissolve in aqueous solutions [11]. The presence of special groups, such as $-\mathrm{OH},-\mathrm{NH}_{2},-\mathrm{SO}_{3} \mathrm{H},-\mathrm{COOH},-\mathrm{CONH}_{2}$ in the three-dimensional network of hydrogels, enables the adsorptive removal and recovery of pollutants from aqueous solutions. In recent years, by occurring new horizons in the field of nanocomposite hydrogels, specific attention has been drawn to the application of clay-based nanocomposite hydrogels in adsorption technology. Polymer-clay nanocomposite hydrogels 
consist of a three-dimensional and crosslinked hydrogel matrix reinforced with clay mineral layers [12]. It has been confirmed that the clay mineral layers can act as reactive crosslinkers in the structure of nanocomposite hydrogels [13]. The incorporation of clay mineral layers into the network of the hydrogels improves the mechanical properties, thermal stability and adsorption efficiency of the matrix material [14]. Among the clays, special attentions have been drawn to montmorillonite (MMT) in the production of nanocomposite hydrogels and also in the removal of organic pollutants and dyes due to its high cation exchange capacity (CEC), excellent swelling ability and existence of functional charged surfaces [15, 16]. Kang et al. [17] prepared nanocomposite hydrogels with exfoliated MMT in chitosan as adsorbents for removing MB from aqueous solutions. The experimental results demonstrated that the adsorption of MB onto the nanocomposite hydrogel adsorbents could be realized through cation exchange. The experimental adsorption results followed the pseudo-second-order kinetics and Langmuir isotherm models. It was also found that the nanocomposite hydrogels prepared with a lower loading level of MMT had a looser stratified structure and a higher adsorption capacity of MB in aqueous solutions. Dai et al. [18] employed polyvinyl alcohol (PVA)/carboxymethyl cellulosebased super adsorbent hydrogel reinforced with bentonite and graphene oxide as an efficient adsorbent for MB removal. The use of bentonite and graphene oxide as fillers increased the formation of porous structure in the adsorbent and improved swelling and thermal stability and MB adsorption efficiency. MB adsorption data were fitted by Langmuir isotherm and pseudosecond-order kinetic model. Wang and coworkers [19] prepared a three-dimensional reticularstructured hydrogel with preferable adsorbability for MB in wastewater treatment. They cooperated MMT with acrylic acid and acrylamide via polymerization, hydrogen-bond, amidation and electrostatic interactions to form the three-dimensional reticular-structured 
hydrogel. The results showed that the pseudo-first-order and pseudo-second-order kinetic models could fit the MB adsorption process, and the adsorption isotherm corresponded to the Sips model. Recently, Qi et al. [20] prepared composite hydrogel adsorbents for dye adsorption by incorporating polydopamine and MMT into the pullulan hydrogel matrix. Their results confirmed the excellent performances of the prepared hydrogel adsorbents in the adsorption process. They concluded that the adsorbents had tunable properties, which can be obtained by manipulating the polydopamine/MMT weight ratio. A series of nanocomposite hydrogel adsorbents based on PVA and MMT was prepared by Roufegari-Nejhad and coworkers [21] via a repeatedly freezing-thawing technique. The abilities of the nanocomposite hydrogel adsorbents in the MB adsorption process were investigated in aqueous solutions with several temperatures, pHs and $\mathrm{MB}$ concentrations. It was found that the contribution of each parameter on the MB removal was in the following order: temperature > concentration of MB in solution > MMT loading level in adsorbent $>\mathrm{pH}$.

Our previous studies introduced a novel series of natural-synthetic bionanocomposite hydrogels based on EW and PVA crosslinked by MMT clay [22]. The applications of the introduced EW/PVA/MMT bionanocomposite hydrogels as wound dressings [23, 24] and drug delivery systems [25] were successfully studied. However, there is no report in the literature on the feasibility of using these novel bionanocomposite hydrogels for adsorption and wastewater treatment applications.

In the current work, EW/PVA/MMT bionanocomposite hydrogels were prepared using a repeatedly freezing-thawing technique and the prepared samples were examined as novel adsorbents for removal of $\mathrm{MB}$ dye from aqueous solutions. The achieved bionanocomposite hydrogel adsorbents (BHAs) were characterized using X-ray diffraction (XRD), field emission 
scanning electron microscopy (FESEM) and Brunauer-Emmett-Teller (BET) analysis. The effects of MMT loading level on the gel content, swelling kinetics and MB desorption abilities of the prepared BHAs were investigated. The Taguchi method was used to optimize the adsorption factors in batch process mode. In addition, the isotherm and kinetic modeling were performed to investigate the adsorption mechanism by fitting the experimental adsorption results to some isotherms and kinetic models.

\section{Materials and Methods}

\section{Materials}

Chicken eggs were bought from a local store in the Urmia area. The eggs were cracked and the white separated carefully from the egg yolk and was used to prepare BHAs with no further purification. The $\mathrm{pH}$ and humidity of $\mathrm{EW}$ were measured on average as 4.7 and 86 wt.\%, respectively. PVA with an average molecular weight of 74800 , a density of $1.25 \mathrm{~g} / \mathrm{cm}^{3}$ and a degree of hydrolysis higher than $98 \%$ was purchased from Nippon Gohsei (The Nippon Synthetic Chemical Industry Co. Ltd), Japan. The clay used in this study was MMT $\left((\mathrm{Na}, \mathrm{Ca})_{0.33}(\mathrm{Al}, \mathrm{Mg})_{2} \mathrm{Si}_{4} \mathrm{O}_{10}(\mathrm{OH})_{2}, \mathrm{nH}_{2} \mathrm{O}\right)$ having a $\mathrm{CEC}$ of 92.6 meq/100g and a density of 2.86 $\mathrm{g} / \mathrm{cm}^{3}$, which was purchased from Southern Clay Products Inc., USA. MB (basic blue 9, chemical formula: $\mathrm{C}_{16} \mathrm{H}_{18} \mathrm{ClN}_{3} \mathrm{~S} \cdot 3 \mathrm{H}_{2} \mathrm{O}$, C.I.: 52015, MW: 373.9) was purchased from Gurr (UK) and used in experiments with no more purification. Britton-Robinson buffers (BRB) with the $\mathrm{pH}$ of 4, 7 and 9 were used throughout the experiments for the swelling and adsorption measurements. Double-distilled water (DDW) was utilized for preparing all solutions and BHAs. 


\section{Preparation of BHAs}

For the preparation of each BHA, two individual dispersions, including PVA/MMT and EW/MMT dispersions, were separately prepared in DDW. For PVA/MMT dispersion, MMT was dispersed in DDW by a magnetic stirrer at $500 \mathrm{rpm}$ for $12 \mathrm{~h}$ at room temperature. The dispersion temperature was then increased to $90{ }^{\circ} \mathrm{C}$ and a predetermined amount of PVA powder was gently dissolved in the prepared MMT dispersion under a continuous mixing of $50 \mathrm{rpm}$ for $4 \mathrm{~h}$. Subsequently, the final dispersion was cooled down to room temperature. For EW/MMT dispersion, first, MMT dispersion was prepared by mixing MMT in DDW. EW was separately mixed for $1 \mathrm{~h}$ to obtain a homogeneous viscous solution. Later, an adequate EW solution was added to the MMT dispersion and mixed at room temperature at a mixing rate of $50 \mathrm{rpm}$ for $4 \mathrm{~h}$. Eventually, the prepared EW/MMT dispersion was added to the PVA/MMT dispersion at room temperature and mixed at $50 \mathrm{rpm}$ for $2 \mathrm{~h}$. The final dispersion was poured into cylindrical plastic molds with a diameter of $15 \mathrm{~mm}$. Afterward, the freezing-thawing technique (freezing temperature: $-20{ }^{\circ} \mathrm{C}$, freezing time: $24 \mathrm{~h}$, thawing temperature: room temperature and thawing time: $24 \mathrm{~h}$ ) was utilized to crosslink the BHAs by repeating the freezing-thawing cycle three times for each EW/PVA/MMT dispersion. Then the achieved BHAs were cut into discs with an approximate thickness of $10 \mathrm{~mm}$. The prepared BHAs had 0, 4 and $8 \mathrm{wt} \%$ of MMT (based on the weight of the dried sample). The samples were named HAx which $\mathrm{x}$ demonstrates the weight percentage of MMT in the dried BHA. The sample designations and compositions of the prepared BHAs in the dried state are tabulated in Table 1. 


\section{Characterizations}

The morphology and structure of BHAs are required to be studied since the MB adsorption process depends directly on the structural and morphological characteristics of BHA. The microstructural aspects of the BHAs were observed by employing a high-resolution field emission scanning electron microscope (Tescan, Mira III, Czech Republic) with an acceleration voltage of $10 \mathrm{kV}$. The HA0 and HA8 samples were dried under vacuum and broken after cooling in liquid nitrogen for this test. The gold powder as a conductive coating for imaging purposes was subsequently sputtered onto the samples. The XRD technique was utilized to determine the morphology of BHAs. The XRD patterns of the pristine MMT and dried HA0 and HA8 samples were obtained using a PW1730 diffractometer (Philips, PW1730, Netherlands) equipped with an $\mathrm{X}$-ray generator using $\mathrm{CuK}_{\alpha}$ radiation $(\lambda=15406 \mathrm{~nm})$ at room temperature. The XRD data were collected over the $2 \theta$ range of $2-80^{\circ}$ with a scanning speed of $2 \% \mathrm{~min}$. BET analysis was carried out to investigate the microstructural characteristics of BHAs, e.g. the surface area and mean pore diameter. The analysis was carried out on HA0 and HA8 samples using a BELSORP-miniII nitrogen adsorption/desorption system (BEL Japan Inc., Japan) at $77 \mathrm{~K}$. Prior to the test, the samples were dried under vacuum and then the amount of nitrogen gas absorbed by each BHA was measured by gently increasing the nitrogen gas pressure. Finally, the amount of nitrogen desorption was determined by decreasing the gas pressure.

\section{Gel content measurement}

The percentage of crosslinked polymeric chains of PVA and protein chains of EW in the existence of MMT were determined for each BHA using the gel content test. The results lead to the evaluation of the influence of MMT loading level on the gel content of BHAs. For this 
purpose, after drying a small piece of each BHA under vacuum $\left(\mathrm{m}_{\mathrm{i}}\right)$, it was submerged in the excess volume of DDW for seven days. During this period, the DDW was replaced several times to facilitate the extraction of uncrosslinked species. Eventually, the sample was moved out from DDW and dried under vacuum until it reached a constant weight $\left(\mathrm{m}_{\mathrm{f}}\right)$. The weights of BHA before and after the extraction were compared and the following equation determined the gel content value:

Gel content $(\%)=\frac{m_{f}}{m_{i}} \times 100$

\section{Swelling study}

The $\mathrm{pH}$-sensitive behavior of BHAs was investigated by obtaining the swelling kinetics of each BHA as a function of time at swelling pHs of 4, 7 and 9. First, $1 \mathrm{~g}$ of each BHA was submerged in an excess volume of DDW for seven days to extract uncrosslinked specimens. During this time, DDW was replaced several times. Each BHA was then withdrawn from DDW and dried under vacuum until a constant weight was reached $\left(\mathrm{m}_{0}\right)$. The $\mathrm{pH}$-depended swelling kinetics of each BHA was determined at $37{ }^{\circ} \mathrm{C}$ by immersing each completely dried sample in $150 \mathrm{ml}$ of BRB solution with $\mathrm{pHs}$ of 4,7 and 9 . While the samples reached the equilibrium swelling, the BHAs were periodically removed. The excess solution on the surface of the sample was removed by blotting with absorbent paper and the weight of the swollen samples was recorded $\left(\mathrm{m}_{\mathrm{t}}\right)$. Finally, the swelling ratio $\left(\mathrm{q}_{\mathrm{t}}\right)$ of each sample at any desired $\mathrm{pH}$ was calculated as follows:

$q_{t}=\frac{m_{t}}{m_{0}}$ 


\section{Determination of MB calibration curves}

To prepare MB solutions, first, $0.1 \mathrm{~g}$ of MB was dissolved in each buffer solution with $\mathrm{pH}$ of 4, 7 and 9 to obtain $100 \mathrm{mg} / \mathrm{L}$ of each stock solution. The required standard solutions with various concentrations were subsequently prepared by further dilutions of each stock solution. In order to determine the maximum absorption wavelength of MB solutions, a UV-Vis Array spectrometer (SP-3000 plus, Japan) in the wavelength range of 400-800 $\mathrm{nm}$ was used. The maximum visible absorbance was obtained at a wavelength of $664 \mathrm{~nm}$, as shown in Fig.1. The calibration curves were achieved by plotting the absorbance values versus the concentration of MB solution (Fig.2).

\section{Measurement of the diffusion coefficient}

The diffusion coefficient of MB in the BHAs was investigated based on the diaphragm cell technique [26]. The cell consisted of two $70 \mathrm{ml}$ compartments separated by a $30 \mathrm{~mm}$ diameter and $3 \mathrm{~mm}$ thick membrane prepared by the BHA sample. Each prepared BHA sample was immersed in an excess volume of DDW for 2 hours before the experiment. The first compartment (donor) contained $10 \mathrm{mg} / \mathrm{L}$ of $\mathrm{MB}$ solution and the other compartment consisted of pure BRB solution (receptor). The system was kept at ambient temperature and stirred continuously for preparing homogeneous conditions in each compartment. At appropriate time intervals, $1 \mathrm{ml}$ of the donor and receptor solutions were taken from each compartment and analyzed by UV-spectrophotometry at $664 \mathrm{~nm}$. The diffusion coefficient data was calculated based on the obtained $\mathrm{MB}$ concentration versus time curves at $\mathrm{pH}$ of 4,7 and 9 using the following equations:

$D=\frac{1}{\beta} \ln (X)$ 
$X=\frac{C_{d}(t)-C_{r}(t)}{C_{d-I n}-C_{r-I n}}$

$\beta=\frac{A}{H}\left(\frac{1}{V_{d}}+\frac{1}{V_{r}}\right)$

where, $\mathrm{H}$ and $\mathrm{A}$ are the thickness and effective crosssection area of the BHA sample, respectively. $V_{r}$ and $V_{d}$ are the volume of the receptor and donor compartments, respectively. $t$ stands for time and $\mathrm{C}_{\mathrm{d}}(\mathrm{t})$ and $\mathrm{C}_{\mathrm{r}}(\mathrm{t})$ are the concentrations of $\mathrm{MB}$ in the donor and receptor solutions at time $\mathrm{t}$, respectively. $\mathrm{C}_{\mathrm{d}-\mathrm{In}}$ is the concentration of $\mathrm{MB}$ in the donor compartment at $\mathrm{t}=0$ $(10 \mathrm{mg} / \mathrm{L})$ and $\mathrm{C}_{\mathrm{r}-\mathrm{In}}$ is the $\mathrm{MB}$ concentration in the receptor compartment at $\mathrm{t}=0(0 \mathrm{mg} / \mathrm{L})$.

\section{Adsorption experiment}

To study the adsorption abilities of the BHAs, the batch mode adsorption experiment was utilized. Individual MB solutions, including 5, 10 and $15 \mathrm{mg} / \mathrm{L}$ of dye with various $\mathrm{pH}$ levels of 4, 7 and 9 were prepared by further diluting the MB stock solutions. Then, pieces of the same weight of the BHAs (ca. $0.2 \mathrm{~g}$ ) were immersed in each adsorption solution $(100 \mathrm{ml})$ at $37{ }^{\circ} \mathrm{C}$. The residual MB concentration in each solution was analyzed in predetermined time intervals by the UV-vis spectrophotometer at $\lambda=664 \mathrm{~nm}$. The adsorption capacity $\left(\mathrm{q}_{\mathrm{e}}\right)$ and the percentage removal of $\mathrm{MB}(\mathrm{R} \%)$ were calculated by the following equations:

$q_{e}=\frac{V\left(C_{0}-C_{e}\right)}{m}$

$R \%=\left(\frac{C_{0}-C_{e}}{C_{0}}\right) \times 100$

where, $\mathrm{V}$ is the solution volume (L) and $\mathrm{m}$ is the adsorbent mass $(\mathrm{g}) . \mathrm{C}_{0}(\mathrm{mg} / \mathrm{L})$ and $\mathrm{C}_{\mathrm{e}}(\mathrm{mg} / \mathrm{L})$ are the MB initial and equilibrium concentrations in the adsorption solution, respectively. 


\section{Experimental design using Taguchi methodology}

Taguchi experimental design method involving an orthogonal array, L9, was employed to study the effects of various parameters for reaching the maximum $\mathrm{MB}$ removal and determine the optimum adsorption conditions. This method was used to investigate the influences of three important operating parameters i.e., MMT loading level in BHA, pH of adsorption solution and MB initial concentration in adsorption solution on the adsorption process. All the experiments were performed in triplicate and the average values were used for analysis. The operational parameters with three levels and experimental design matrix are listed in Tables 2 and 3. In Taguchi design, the signal to noise $(\mathrm{S} / \mathrm{N})$ ratio is used as a performance factor to evaluate the experimental results. The $\mathrm{S} / \mathrm{N}$ ratio was analyzed by Minitab19 software to estimate the experimental results and their suitability in determining the quality characteristics. The aim of the current study was to maximize the $\mathrm{MB}$ removal. The $\mathrm{S} / \mathrm{N}$ ratio was determined by the following equation:

$\frac{S}{N}=-10 \log \left(\frac{1}{n} \sum_{i=1}^{n} \frac{1}{y_{i}^{2}}\right)$

where, $\mathrm{n}$ is the number of experimental tests and $\mathrm{y}_{\mathrm{i}}$ is the experimentally achieved performance data (MB removal percent). Additionally, analysis of variance (ANOVA) was utilized to identify the most influential factor in the adsorption process.

\section{Desorption study}

Desorption and retrieval are the critical factors for an adsorbent to reduce its cost, minimize the amount of waste and recover the adsorbent to be appropriate for industrial applications. To remove the adsorbed dye from the MB-loaded adsorbents, the following desorption experiment 
was conducted. In the first stage, the dye-loaded BHAs at adsorption equilibrium conditions were separated from the MB solution $\left(\mathrm{C}_{0}=10 \mathrm{mg} / \mathrm{L}\right.$ for $\left.24 \mathrm{~h}\right)$ and they were gently washed with DDW to remove the non-adsorbed MB molecules. Then, the dye-loaded adsorbents were separately immersed into $100 \mathrm{ml}$ of acetic acid solutions $(0.04 \mathrm{M})$ at $30{ }^{\circ} \mathrm{C}$ for $24 \mathrm{~h}$. The amount of desorbed MB was determined by UV-visible spectroscopy. The desorption percentage (\% Desorption) was calculated using the Eq. (9):

$\%$ Desorption $=\frac{\text { Concentration desorbed }}{\text { Concentration adsorbed }}$

\section{Results and Discussion}

\section{Microstructural and morphological characteristics}

XRD analysis was used to investigate the microstructural characteristics of BHAs and determine the morphology of the MMT mineral layers within the three-dimensional structure of adsorbents. The XRD patterns of the pristine MMT, MMT-free BHA (HA0 sample) and BHA loaded with 8 wt.\% of MMT (HA8 sample) are shown in Fig. 3. In general, the formation of the nanocomposite structure and determination of the morphology of the prepared nanocomposite (i.e., intercalated or exfoliated morphologies) could be confirmed by comparing the XRD patterns of pristine MMT powder and MMT-loaded composite samples. As is observed in Fig. 3, the MMT crystals show characteristic reflections at around $7.4,20.1,28.6,35.4,54.0,62.2,73.7$ and $76.6^{\circ}$, while similar results have also been reported in the literature [27, 28]. However, the characteristic reflection of MMT at $2 \theta=7.4^{\circ}$ has been disappeared in the XRD profile of the HA8 sample, indicating the MMT mineral layer has been successfully disturbed and exfoliated in the EW/PVA hydrogel matrix. On the other hand, the presence of peaks around 20 and $40^{\circ}$ in MMT- 
free sample (HA0) and MMT-loaded hydrogel adsorbent (HA8) clearly indicates the creation of semi-crystalline domains as a result of the freezing-thawing cycles.

The cryogenic fractured surface morphology of two typical samples (HA0 and HA8) was analyzed using FESEM and the obtained micrographs are depicted in Fig. 4. MMT-free BHA displayed a porous structure containing a wide pore size distribution. In addition, MMT clay inclusion is seen in the structure of the HA8 sample that enhances the crosslinked zones compared to the HA0 sample and reduces the pore size and creates a relatively tight structure with the distribution of some bulges.

Porous structure parameters of BHAs were evaluated based on BET and Barrett-Joyner-Halenda (BJH) analysis. The achieved adsorption-desorption profiles for the HA0 and HA8 adsorbents obtained from the BET analysis in liquid nitrogen at $77 \mathrm{~K}$ are demonstrated in Fig. 5. Both samples have the index of mesopores hysteresis, and based on the International Union of Pure and Applied Chemistry classification, the shape of the pores in the adsorbents are slit-shaped [29]. Some porous structure parameters obtained from the BET and BJH analysis are tabulated in Table 4. It can be seen that adding $8 \mathrm{wt} . \%$ of MMT to the adsorbent decreases its total pore volume and mean pore diameter by 28.5 and $22.9 \%$, respectively. It can be deduced that the existence of MMT mineral layers creates a more interconnected-porous network with the micropores inside the hydrogel matrix of the BHA samples, which confirms the FESEM results. These micropores in the adsorbent structure permit water penetration and retention in the polymer network, making the prepared adsorbents suitable for pollutant adsorption.

The gel content values of the prepared BHAs are shown in Fig. 6. All BHAs had a gel content value higher than $85 \%$, depending on the content of incorporated MMT into the samples. In the MMT-free sample, the traditional crosslinking is formed via the crystallization of EW and PVA 
chains during the freezing-thawing process, while by adding MMT into the hydrogel matrix and increasing the MMT content, a more entangled and crosslinked network was established. The high gel content of BHAs in the existence of MMT mineral layers deduces the creation of some interactions between the EW/PVA matrix and MMT mineral layers, proving the role of MMT mineral layers as physical crosslinkers in the structure of BHAs.

\section{pH-sensitive swelling behavior}

The influence of the $\mathrm{pH}$ of the swelling medium on the swelling kinetics of the prepared BHAs was studied at three different pHs (i.e., 4, 7 and 9) and the results are depicted in Fig. 7. Over time, all the prepared BHAs swelled and exhibited an almost identical swelling profile at all media. It was found that the swelling ratios of the prepared BHAs significantly increased with increasing the $\mathrm{pH}$ of the swelling medium and decreased with increasing the MMT content. The clay-free sample exhibited a higher swelling ratio than samples loaded with 4 and 8 wt.\% of clay in all swelling media. The reduction in swelling ratio of MMT-loaded samples could be due to alteration of hydrogel network structure caused by the incorporation of MMT. In fact, MMT mineral layers dispersed in the matrix of BHA act as barriers, making it difficult for the solvent molecules to move. It is obvious that the swelling process depends extremely on the structure of the hydrogel network. At acidic conditions ( $\mathrm{pH}=4)$, most of the hydroxyl groups available in the network of BHAs are protonated. Thus, the hydrogel network tends to shrink and the swelling ratio is decreased in an acidic medium. While with increasing $\mathrm{pH}$, the electrostatic repulsion among the protein and polymeric chains is increased due to increasing the number of $\mathrm{OH}^{-}$ions in the medium and as a result, the swelling ability of hydrogel is enhanced. Furthermore, the electrostatic interaction between the $\mathrm{Na}^{+}$ions (available in the interlayer spacing of the MMT) 
and the $\mathrm{OH}^{-}$ions in the basic medium could be considered an additional reason for the increased swelling of BHAs in the basic solution $(\mathrm{pH}=9)$.

The effects of MMT content and $\mathrm{pH}$ of the swelling medium on the equilibrium swelling ratio $\left(\mathrm{q}_{\infty}\right)$ of BHAs are shown in Fig. 8. Obviously, the equilibrium swelling ratio tended to increase by decreasing the percentage of clay particles in the samples and increasing the $\mathrm{pH}$ of the swelling medium. For instance, the equilibrium swelling ratio in a clay-free sample was 11.8 at $\mathrm{pH}=9$, while this value for the adsorbent loaded with 8 wt.\% of MMT at the same $\mathrm{pH}$ was 4.6. Figure 8 also shows a meaningful dependency of the equilibrium swelling ratio of BHAs on the $\mathrm{pH}$ of the swelling medium. For example, the equilibrium swelling ratio of the HA4 adsorbent increased from 3.1 to 6.1 , with increasing the $\mathrm{pH}$ from 4 to 9 . As previously mentioned, the electrostatic repulsion among the chains of the hydrogel network becomes stronger in the basic mediums, which finally leads to the expansion of the BHA network.

\section{MB diffusion coefficient}

MB diffusion coefficient in BHAs was determined through the variations of the MB concentration in donor and receptor compartments of a diaphragm cell system at $37{ }^{\circ} \mathrm{C}$ and $\mathrm{pH}$ of 4, 7 and 9 and the obtained concentration curves versus time are shown in Fig. 9. As expected, the $\mathrm{MB}$ concentration decreased in the donor compartment and increased in the receptor compartment over time. However, the obtained values for both compartments are not consistent since a part of the MB molecules was adsorbed and trapped in the BHA sample. The MB diffusion coefficient for each sample at known $\mathrm{pH}$ was determined from the slope of the $-\ln (\mathrm{x})$ curve against time (Fig. 10) and the obtained diffusion coefficients are listed in Table 5. It is obvious that the diffusion coefficient of MB under similar conditions decreases with increasing 
MMT content. In general, the diffusion coefficient of a solute in a polymeric network or hydrogel is a function of the average pore size of the network, the polymeric chains mobility and the mobility of the solvent molecules in the network [30]. Thus, the decrease of MB diffusion coefficient with increasing MMT content in BHAs can be essentially related to the reduced mobility of the proteins and polymer chains caused by increasing gel content value and crosslinking intensity. On the other hand, according to the FESEM and BET results, the reduction in the pore size induced by MMT loading is expected to reduce the MB diffusion coefficient in clay-loaded BHAs. The presented results in Table 5 also exhibit that the MB diffusion coefficient is dependent on the $\mathrm{pH}$ of the solution. By increasing the $\mathrm{pH}$ value, the $\mathrm{MB}$ diffusion coefficient is increased. In other words, the MB molecules have a higher diffusion rate in the alkaline environment compared to the acidic one. As discussed previously, when the $\mathrm{pH}$ of the solution rises, repulsion forces among the hydroxyl group of the hydrogel network and the ions present in the buffer solution cause the hydrogel network to undergo more swelling and therefore, the diffusion of MB molecules into the network is facilitated.

\section{Analysis of adsorption data}

The Taguchi method was used to recognize the most significant levels of the selected operational parameters (i.e., MMT loading level in BHA, $\mathrm{pH}$ of adsorption solution and $\mathrm{MB}$ initial concentration in adsorption solution) on the $\mathrm{MB}$ adsorption. The $\mathrm{MB}$ average removal percentage values and their equivalent $\mathrm{S} / \mathrm{N}$ ratio were calculated and are presented in Table 3. The S/N ratio response graphs as functions of the level of the parameters are also demonstrated in Fig. 11. The results show that the mean removal percentage of MB varied from 11.04 to 50.02 $\%$, while the $\mathrm{S} / \mathrm{N}$ ratio was in the range of 22.29 to 31.92 . The highest response value represents 
the best level for each operational parameter and is interpreted as the optimal value for the intended parameter. Therefore, based on the $\mathrm{S} / \mathrm{N}$ ratio, the optimal parameters for $\mathrm{MB}$ removal are $\mathrm{A}: \mathrm{pH}$ at level $3(\mathrm{pH}=9), \mathrm{B}$ : weight percentage of MMT at level $3(8 \%)$ and $\mathrm{C}$ : MB initial concentration at level $1(5 \mathrm{mg} / \mathrm{L})$. One of the crucial parameters in the treatment of cationic dyes is $\mathrm{pH}$ because the surface charge of the hydrogel adsorbents can change by varying the $\mathrm{pH}$ of the solution [31]. Figure 11 indicates that the $\mathrm{S} / \mathrm{N}$ ratio increased by increasing the $\mathrm{pH}$ value from 4 to 9. The increasing tendency of $\mathrm{MB}$ adsorption by increasing the $\mathrm{pH}$ value can be attributed to the accumulation of the negative hydroxyl ions present in the basic medium, which increases the number of negatively charged sites on the adsorbent, prevents the probable competition between different positive charges and consequently, intensifies the MB cationic dye adsorption onto the surface of the adsorbent. On the other hand, these electrostatic forces cause repulsion between the hydrogel chains, so the hydrogel network tends to swell. This phenomenon leads to an increase in the transfer of the MB molecules during the swelling and, thus, the enhancement of the adsorption of MB onto the adsorbent's surface. Similar data have also been reported in the literature [32, 33]. Figure 11 also shows that the MMT loading level in BHAs is another important factor affecting the adsorption of the MB. By increasing the loading level of MMT in BHAs, the $\mathrm{S} / \mathrm{N}$ ratio is significantly increased. Accordingly, HA8 is the best adsorbent for MB adsorption. Increase in the dye removal percent at high MMT loading levels can be related to the electrostatic interactions created between the negatively charged surfaces of clay mineral layers and positive cations of dye. Similar data have been reported regarding the influence of MMT content on the MB removal by MMT-loaded adsorbents [21, 34]. Figure 11 shows that the $\mathrm{S} / \mathrm{N}$ ratio is restricted and decreased by increasing the initial concentration of the MB solution. It is clear that $\mathrm{MB}$ removal is influenced by the $\mathrm{MB}$ initial concentration and the $\mathrm{MB}$ removal 
percentage decreases by increasing the $\mathrm{MB}$ concentration. At the beginning of the removal process, the adsorption of MB is carried out on the surface of the adsorbent and afterward, the MB molecules gently penetrate the interior part of the adsorbent. With the progress of adsorption, the active sites on the adsorbent surface are saturated by MB molecules and the repulsion forces between MB molecules concentrated on the surface prevent dye penetration into the three-dimensional network of BHAs, which causes the decrease of the adsorption rate.

The model results were statistically analyzed to assess the appropriateness of the model by taking into account the functions, e.g. degree of freedom, mean square, sum of squares, F-ratio and pvalue (Table 6). The high values of F-ratio and corresponding p-values $(<0.05)$ showed that all factors are statistically significant. Also, the MMT loading level was found to be the most affecting parameter on the adsorption process.

\section{Adsorption kinetics}

Adsorption kinetic study is a useful way to understand the adsorption process since it can be utilized to describe the adsorption rate and discover the adsorption mechanism. In this study, kinetic modeling was performed to evaluate the effects of MB initial concentration $(5,10$ and 15 $\mathrm{mg} / \mathrm{L}$ ) on adsorption uptake at optimal adsorption conditions (HA8 adsorbent at $\mathrm{pH}=9$ ) at $37^{\circ} \mathrm{C}$. The experimental kinetic data at the equilibrium contact time were analyzed by the pseudo-firstorder, pseudo-second-order, Elovich and intra-particle diffusion models to investigate the mechanism of the MB adsorption process. To determine the best kinetic model describing the interaction between the adsorbent and MB molecules, the coefficient of correlation $\left(\mathrm{R}^{2}\right)$ and sum-of-squared errors (SSE) were employed. SSE is given by Eq. (10): 
$\operatorname{SSE}(\%)=\sqrt{\frac{\sum\left(q_{e-\exp }-q_{e-c a l}\right)^{2}}{N}}$

where, $N$ is the number of data points and $\mathrm{q}_{\mathrm{e}-\mathrm{exp}}$ and $\mathrm{q}_{\mathrm{e}-\mathrm{cal}}$ are the experimental and calculated values of $\mathrm{q}_{\mathrm{e}}$, respectively. All the used kinetic models and their parameters and also calculated values of $\mathrm{R}^{2}$ and SSE are tabulated in Table 7. The compatibility order of the studied kinetic models with the adsorption data obtained through the experiment is as follows:

Intra-particle diffusion > pseudo-first-order $>$ Elovich $>$ Pseudo-second-order

A comparison of the adsorption capacity calculated by the kinetic models with the experimental data is presented in Fig. 12. As shown, the intra-particle diffusion model provided the best fit for all the studied concentration range with $\mathrm{R}^{2}$ values above 0.96 . In addition, the difference between the experimental and the obtained theoretical adsorption capacity at equilibrium conditions is relatively low in this model. Thus, based on these results, the intra-particle diffusion kinetic model is more suitable for describing the adsorption kinetic data. According to this model, various mechanisms are involved in the MB adsorption process in three steps: external surface adsorption, intra-particle diffusion (the speed-limiting step) and the final equilibrium [35]. On the other hand, from the results presented in Table 7, it is clear that I values (boundary layer thickness) are not zero and boundary layer diffusion partly controls the MB adsorption process. The other studied models were less consistent with the experimental data, so they cannot well explain the mechanism of MB adsorption onto BHAs.

\section{Adsorption isotherms}

Modeling of adsorption isotherm data is one of the most significant methods for predicting and comparing adsorption performance that can be used to appraise the adsorption capacities and the 
effective design of the adsorption systems. To investigate the adsorption isotherms, the experiments were performed using the optimal conditions obtained by Taguchi design with a contact time of 720 min at different temperatures (i.e., 30, 40 and $50{ }^{\circ} \mathrm{C}$ ). Four models, including the Langmuir, Freundlich, Temkin and Dubinin-Radushkevich were utilized to investigate the adsorption isotherms. The first isotherm model used in this study was the Langmuir isotherm, which is defined in a linear form as follows:

$\frac{C_{e}}{q_{e}}=\frac{C_{e}}{q_{m}}+\frac{1}{K_{L} q_{m}}$

where, $\mathrm{C}_{\mathrm{e}}$ is the $\mathrm{MB}$ equilibrium concentration $(\mathrm{mg} / \mathrm{L})$ and $\mathrm{K}_{\mathrm{L}}(\mathrm{L} / \mathrm{mg})$ and $\mathrm{q}_{\mathrm{m}}(\mathrm{mg} / \mathrm{g})$ are constants that are related to monolayer adsorption capacity and energy (i.e., net enthalpy) of adsorption, respectively. To determine if the MB adsorption by our prepared sample (HA8) is favorable or unfavorable for the Langmuir type adsorption process, a dimensionless constant $\left(R_{L}\right)$ known as separation factor was utilized as defined below:

$R_{L}=\frac{1}{1+K_{L} C_{0}}$

$R_{L}$ value to be either unfavorable if $R_{L}>1$, linear if $R_{L}=1$, favorable if $0<R_{L}<1$ and irreversible if $R_{L}=0$. The second isotherm model used in this study was the Freundlich isotherm, which is defined as:

$\log q_{e}=\log K_{F}+\frac{1}{n} \times \log C_{e}$

where, $\mathrm{n}$ is the adsorption intensity and $\mathrm{K}_{\mathrm{F}}$ is an indicator of the adsorption capacity $(\mathrm{mg} / \mathrm{g})$. The Temkin isotherm is generally applied in the following form:

$q_{e}=B \ln \left(K_{T}\right)+B \ln \left(C_{e}\right)$

where, $B$ is a constant related to the heat of adsorption and $\mathrm{K}_{\mathrm{T}}(\mathrm{L} / \mathrm{mg})$ is the equilibrium binding constant corresponded to the maximum binding energy. Due to the excellent fitting performance 
of the Dubinin-Radushkevich isotherm model, this model is most commonly used to describe single-solute adsorption. The Dubinin-Radushkevich isotherm is more general than the Langmuir isotherm since it does not assume a homogenous surface or constant sorption potential. DubininRadushkevich isotherm is defined as follows:

$\ln q_{e}=\ln \left(q_{m}\right)-K_{D R} \varepsilon^{2}$

where $\varepsilon(\mathrm{kJ} / \mathrm{mol})$ is the adsorption potential and $K_{D R}\left(\mathrm{~mol}^{2} / \mathrm{kJ}{ }^{2}\right)$ is a constant associated with the adsorption energy. The adsorption potential was calculated using the following equation:

$\varepsilon=R T \ln \left[1+\frac{1}{C_{e}}\right]$

where, $\mathrm{T}$ is the temperature $(\mathrm{K})$ and $\mathrm{R}$ is the universal gas constant $(8.314 \mathrm{~J} / \mathrm{mol} . \mathrm{K})$. The equilibrium isotherm data and isotherm model curves and parameters obtained by processing the experimental results are compared in Fig. 13 and Table 8. Based on the coefficient of correlation reported in Table 8, the Langmuir model is the first and the Dubinin-Radushkevich model is the second-best fitted model to experimental data, which provides an accurate description of the experimental results. The Langmuir isotherm represents the monolayer coverage of the adsorption of MB molecules at the outer surface of the HA8 adsorbent. The results show that the obtained $\mathrm{q}_{\mathrm{m}}$ values increased with increasing temperature, confirming that the studied system is an endothermic adsorption process. Increasing the adsorption capacity by increasing temperature can be due to the faster movement of MB molecules and also enhancement of the swelling ability of BHA at high temperatures [10]. On the other hand, as presented in Table 9, the calculated $R_{L}$ values were between 0 and 1, indicating that the adsorption of MB onto the HA8 surface is a favorable process at all the studied ranges of MB concentration and temperature. 


\section{Desorption results}

Our preliminary desorption experiments showed that the prepared BHAs had no considerable desorption in neutral $\mathrm{pH}$ (DDW), but the desorption process occurred in the acid medium (acetic acid). Failure of the desorption process in DDW clearly indicates that relatively strong interactions are shared between the functional groups of BHA and the MB cationic molecules. The desorption curves of MB-loaded BHAs in acetic acid solution were achieved according to the method described in the experimental section and the obtained data are demonstrated in Fig. 14. According to the achieved desorption curves, $\mathrm{MB}$ desorption is reduced by increasing the clay content in BHAs; thus, the clay-free sample had the highest desorption rate among the adsorbents. The decrease of adsorption capacity in the prepared BHAs by increasing the MMT loading level can be related to the more crosslinked zones created inside the three-dimensional structure of BHA in the existence of MMT mineral layers. The strong interactions created between the cationic MB molecules and negatively charged MMT mineral layers, which seriously restrict the movement of the $\mathrm{MB}$ molecules inside the BHA network, could be recognized as another reason for decreasing the desorption process by increasing the MMT loading level in BHAs.

\section{Conclusion}

Novel BHAs based on EW/PVA bionanocomposite hydrogels loaded with MMT were prepared successfully using a facile repeatedly freezing-thawing method and the performances of the obtained BHAs as novel eco-friendly adsorbents were studied for the efficient MB removal. It was shown that a nanocomposite hydrogel with exfoliated morphology could be achieved by incorporating MMT clay into the EW/PVA network. The obtained results showed that the 
existence of MMT inside the adsorbents increases the gel content and creates a more interconnected-porous hydrogel network inside the BHAs. The results showed that the swelling ratio and $\mathrm{MB}$ diffusion coefficient of $\mathrm{BHAs}$ were increased either by increasing the $\mathrm{pH}$ of the medium or by decreasing the MMT content. The optimum adsorption conditions by the Taguchi

method were determined as montmorillonite loading level of $8 \mathrm{wt} . \%, \mathrm{pH}$ of 9 and methylene blue initial concentration of $5 \mathrm{mg} / \mathrm{L}$. The experimental data obtained from the adsorption test were matched to the intra-particle diffusion kinetic model and Dubinin-Radushkevichs isotherm model. Finally, it can be concluded that the prepared BHAs could be used as eco-friendly efficient adsorbents for the treatment of industrial wastewaters.

\section{Statements and Declarations}

The authors declare that no funds, grants, or other support were received during the preparation of this manuscript.

The authors have no relevant financial or non-financial interests to disclose.

\section{References}

\section{References}

1. Sajid M, Nazal MK, Baig N, Osman, AM (2018) Sep Purif Technol 191:400-423

2. Zhou Y, Lu J, Zhou Y, Liu Y (2019) Environ Pollut 252:352-365

3. Shahidi A, Jalilnejad N, Jalilnejad E (2015) Desalination Water Treat 53(13):3570-3579

4. Baharlouei A, Jalilnejad E, Sirousazar M (2018) Chem Eng Commun 205(11):1537-1554

5. Katheresan V, Kansedo J, Lau SY (2018) J Environ Chem Eng 6(4):4676-4697

6. Yagub MT, Sen TK, Afroze S, Ang HM (2014) Adv Colloid Interface Sci 209:172-184 
7. Kausar A, Iqbal M, Javed A, Aftab K, Bhatti HN, Nouren S (2018) J Mol Liq 256:395-407

8. Bulgariu L, Escudero LB, Bello OS, Iqbal M, Nisar J, Adegoke KA, Anastopoulos I (2019) J Mol Liq 276:728-747

9. Oymak T, Bagda E (2018) Clean (Weinh) 46(6):1700186

10. Shaabani Y, Sirousazar M, Kheiri F (2016) Appl Clay Sci 126:287-296

11. Khan M, Lo IM (2016) Water Res 106:259-271

12. Sirousazar M, Forough M, Farhadi K, Shaabani Y, Molaei R (2014) In: Tiwari A (ed) Advanced healthcare materials, John Wiley \& Sons Inc, Hoboken, NJ, USA, pp 295-357

13. Liu Z, Faraj Y, Ju XJ, Wang W, Xie R, Chu LY (2018) J Polym Sci B Polym Phys 56(19):1306-1313

14. Sangeetha K, Vinodhini PA, Sudha PN (2019) In: Inamuddin, Thomas S, Mishra RK, Asiri A (Eds.) Sustainable polymer composites and nanocomposites, Springer, Cham, pp. 11591183

15. Oskui FN, Aghdasinia H, Sorkhabi MG (2019) Environ Earth Sci 78(4):106

16. Gurses A, Dogar C, Yalcın M, Acıkyildiz M, Bayrak R, Karaca S (2006) J Hazard Mater 131(1-3):217-228

17. Dai H, Huang Y, Huang H (2018) Carbohydr Polym 185:1-11

18. Taghizadeh MT, Sabouri N (2013) Int Nano Lett 3(1): 1-8

19. Wang W, Wang J, Zhao Y, Bai H, Huang M, Zhang T, Song S (2020) Environ Pollut, 257:113574

20. Qi X, Zeng Q, Tong X, Su T, Xie L, Yuan K, Shen J (2021) J Hazard Mater 402:123359

21. Roufegari-Nejhad E, Sirousazar M, Abbasi-Chiyaneh V, Kheiri F (2019) J Polym Environ 27(10):2239-2249 
22. Shaabani Y, Sirousazar M, Kheiri F (2016) J Macromol Sci Part B 55(8):849-865

23. Sirousazar M, Jahani-Javanmardi A, Kheiri F, Hassan ZM (2016) J Biomater Sci Polym Ed 27(16):1569-1583

24. Jahani-Javanmardi A, Sirousazar M, Shaabani Y, Kheiri F (2016) J Biomater Sci Polym Ed 27(12):1262-1276

25. Taleblou N, Sirousazar M, Hassan ZM, Khaligh SG (2020) J Biomater Sci Polym Ed 31(1):72-92

26. Falk B, Garramone S, Shivkumar S (2004) Mater Lett 58(26):3261-3265

27. Wu H, Xie H, He G, Guan Y, Zhang Y (2016) Appl Clay Sci 119:161-169

28. Jeon I, Nam K, (2019) Sci Rep 9(1):1-10

29. Sing KS (1984) Pure Appl Chem 57:603-619

30. Janicijevic Z, Radovanovic F (2018) Polymer 147:56-66

31. Jana S, Ray J, Mondal B, Pradhan SS, Tripathy T (2018) Colloids Surf A Physicochem Eng Asp 553:472-486

32. Shi Y, Xue Z, Wang X, Wang L, Wang A (2013) Polym Bull 70(4):1163-1179

33. Wang L, Zhang J, Wang A (2008) Colloids Surf A Physicochem Eng Asp 322(1-3):47-53

34. Wang W, Zhao Y, Bai H, Zhang T, Ibarra-Galvan V, Song S (2018) Carbohydr Polym 198:518-528

35. Cheung WH, Szeto YS, McKay G (2007) Bioresour Technol 98(15):2897-2904 
Table 1. Designations and chemical compositions of dried BHAs.

\begin{tabular}{cccc}
\hline $\begin{array}{c}\text { Sample } \\
\text { designation }\end{array}$ & $\begin{array}{c}\text { PVA } \\
(\text { wt.\% })\end{array}$ & $\begin{array}{c}\text { Dried EW } \\
(\text { wt. \%) }\end{array}$ & $\begin{array}{c}\text { MMT } \\
(\text { wt. \%) }\end{array}$ \\
\hline HA0 & 66.7 & 33.3 & 0 \\
\hline HA4 & 64.0 & 32.0 & 4 \\
\hline HA8 & 61.3 & 30.7 & 8 \\
\hline
\end{tabular}


Table 2. Factors and their selected levels.

\begin{tabular}{ccccc}
\hline & & \multicolumn{3}{c}{ Levels of factors } \\
\hline Factor & Independent variable & $\mathbf{- 1}$ & $\mathbf{0}$ & $\mathbf{1}$ \\
\hline $\mathbf{A}$ & $\mathrm{pH}$ of adsorption solution & 4 & 7 & 9 \\
\hline B & MMT loading level in BHA & 4 & 8 \\
\hline (wt.\%) & 0 & 10 & 15 \\
\hline
\end{tabular}


Table 3. Design matrix and measured responses with the corresponding S/N ratios.

\begin{tabular}{ccccccc}
\hline Run no. & \multicolumn{3}{c}{ Design matrix } & \multicolumn{3}{c}{ Response } \\
\hline & & Factor & & $\begin{array}{c}\text { MB removal } \\
(\%)\end{array}$ & $\begin{array}{c}q_{e} \\
(\mathrm{mg} / \mathrm{g})\end{array}$ & S/N ratio \\
\hline $\mathbf{1}$ & $\mathrm{A}$ & $\mathrm{B}$ & $\mathrm{C}$ & & & \\
\hline $\mathbf{2}$ & -1 & -1 & -1 & 11.04 & 0.28 & 24.11 \\
\hline $\mathbf{3}$ & -1 & 0 & 0 & 12.41 & 0.62 & 25.64 \\
\hline $\mathbf{4}$ & -1 & 1 & 1 & 30.15 & 2.22 & 28.77 \\
\hline $\mathbf{5}$ & 0 & -1 & 0 & 11.60 & 0.58 & 22.29 \\
\hline $\mathbf{6}$ & 0 & 0 & 1 & 14.84 & 1.10 & 24.30 \\
\hline $\mathbf{7}$ & 0 & 1 & -1 & 40.70 & 1.02 & 31.92 \\
\hline $\mathbf{8}$ & 1 & -1 & 1 & 17.25 & 1.29 & 26.88 \\
\hline & 1 & 0 & -1 & 23.93 & 0.63 & 25.72 \\
\hline
\end{tabular}


Table 4. Porous structure parameters of the selected adsorbents.

\begin{tabular}{lcc}
\hline & HA0 & HA8 \\
\hline BET plot & & \\
\hline Specific surface area $\left(\mathrm{m}^{2} / \mathrm{g}\right)$ & 1.3603 & 1.2603 \\
\hline Monolayer volume $\left[\mathrm{cm}^{3}(\mathrm{STP}) \mathrm{g}\right]$ & 0.3125 & 0.2896 \\
\hline Total pore volume $\left(\mathrm{cm}^{3} / \mathrm{g}\right)$ & 0.003931 & 0.002810 \\
\hline Mean pore diameter $(\mathrm{nm})$ & 11.56 & \\
\hline BJH plot & & \\
\hline Pore volume $\left(\mathrm{cm}^{3} / \mathrm{g}\right)$ & 0.9045907 & 0.0023989 \\
\hline Micropore radius $(\mathrm{nm})$ & & 1.21 \\
\hline Pore specific surface $\operatorname{area}\left(\mathrm{m}^{2} / \mathrm{g}\right)$ & 3.5409 & 1.8504 \\
\hline
\end{tabular}


Table 5. MB diffusion coefficients for BHAs at different $\mathrm{pHs}$.

\begin{tabular}{|c|c|c|}
\hline pH & Sample designation & $\mathrm{D} \times 10^{-10}\left(\mathrm{~m}^{2} / \mathrm{s}\right)$ \\
\hline \multirow{3}{*}{4} & HA0 & 6.731 \\
\hline & HA4 & 4.515 \\
\hline & HA8 & 3.542 \\
\hline \multirow{3}{*}{7} & HAO & 7.034 \\
\hline & HA4 & 4.793 \\
\hline & HA8 & 3.926 \\
\hline \multirow{3}{*}{9} & HA0 & 7.184 \\
\hline & HA4 & 5.023 \\
\hline & HA8 & 4.629 \\
\hline
\end{tabular}


Table 6. Results of ANOVA study.

\begin{tabular}{cccccc}
\hline Source & df & SS & MS & F & $p$-value \\
\hline A: pH of adsorption solution & 2 & 33.822 & 16.910 & 697.71 & 0.001 \\
\hline B: MMT loading level in & 2 & 154.789 & 79.364 & 3193.15 & 0 \\
BHA & & & & & \\
\hline $\begin{array}{c}\text { C: MB initial concentration in } \\
\text { adsorption solution }\end{array}$ & 2 & 2.308 & 1.154 & 47.62 & 0.021 \\
\hline $\begin{array}{c}\text { Residual Error } \\
\text { Total }\end{array}$ & 2 & 0.048 & 0.024 & - & - \\
\hline Model Summary & 8 & 190.968 & - & - & - \\
\hline & $\mathrm{S}=0.1557$ & $\mathrm{R}-\mathrm{Sq}=100.0 \%$ & $\mathrm{R}-\mathrm{Sq}(\mathrm{adj})=99.9 \%$ \\
\end{tabular}


Table 7. Kinetic parameters for pseudo-first-order, pseudo-second-order, Elovich and Intraparticle diffusion adsorption kinetic models.

\section{Kinetic Model}

parameter

\section{MB Initial concentration (mg/L)}

5

10

15

1.520

\begin{tabular}{|c|c|}
\hline$q_{e, e x p}(m g / g)$ & 1.009 \\
\hline
\end{tabular}

\section{Pseudo-first-order}

$\mathbf{q}_{\mathrm{e}, \mathrm{cal}}(\mathrm{mg} / \mathrm{g})$

1.002

4.178

1.759

$\mathrm{k}_{1}(\mathbf{1} / \mathrm{min})$

0.002

0.641

0.079

$\frac{d q_{t}}{d t}=k_{1}\left(q_{e}-q_{t}\right)$

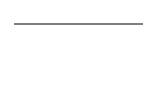

0.934

0.923

0.935

\begin{tabular}{|c|c|c|c|c|}
\hline & SSE & 0.0004 & 3.680 & 0.052 \\
\hline \multirow[b]{2}{*}{ Pseudo-second-order } & $\mathbf{q}_{\mathrm{e}, \mathbf{e x p}}$ & 1.009 & 2.273 & 1.369 \\
\hline & $\mathbf{q}_{\mathrm{e}, \mathrm{cal}}(\mathrm{mg} / \mathrm{g})$ & 1.113 & 8.826 & 3.256 \\
\hline \multirow{3}{*}{$\frac{d q_{t}}{d t}=k_{2}\left(q_{e}-q_{t}\right)^{2}$} & $\mathrm{k}_{2}(\mathrm{~g} / \mathrm{mg} \cdot \mathrm{min})$ & 0.004 & 0.603 & 0.047 \\
\hline & $\mathbf{R}^{2}$ & 0.861 & 0.495 & 0.567 \\
\hline & SSE & 0.034 & 2.180 & 0.629 \\
\hline Elovich & $\alpha(\mathrm{mg} / \mathrm{g} \mathrm{min})$ & 0.008 & 0.026 & 0.013 \\
\hline \multirow{2}{*}{$\frac{d q_{t}}{d t}=\alpha \exp \left(-\beta q_{t}\right)$} & $\beta(\mathrm{g} / \mathrm{mg})$ & 4.789 & 1.240 & 2.444 \\
\hline & $\mathbf{R}^{2}$ & 0.898 & 0.924 & 0.879 \\
\hline \multirow{2}{*}{$\begin{array}{l}\text { Intra-particle } \\
\text { diffusion }\end{array}$} & $k_{i}\left(\mathrm{mg} / g \cdot \min ^{0.5}\right)$ & 0.037 & 0.143 & 0.074 \\
\hline & I & 0.115 & 0.637 & 0.328 \\
\hline$q_{t}=k_{i} t^{0.5}+I$ & $\mathbf{R}^{2}$ & 0.960 & 0.976 & 0.985 \\
\hline
\end{tabular}

qe and qt are MB adsorption capacity of the HA8 sample at equilibrium and at time $\mathrm{t}(\mathrm{min})$, respectively. $\mathrm{k}_{1}$ (1/min) and $\mathrm{k}_{2}$ (mg/g.min) are the rate constants of the pseudo-first-order and pseudo-second-order kinetic models, respectively. $\alpha$ defines the initial rate of adsorption (mg/g. min), $\beta$ is the desorption constant in the Elovich model, $\mathrm{Ki}$ is a rate constant $\left(\mathrm{mg} / \mathrm{g} \cdot \mathrm{min}^{0.5}\right)$ and $\mathrm{I}$ is boundary layer thickness (mg/g). 
Table 8. Langmuir, Freundlich, Temkin and Dubinin-Radushkevich isotherm parameters at different temperatures for MB adsorption onto HA8 adsorbent.

\begin{tabular}{|c|c|c|c|c|}
\hline \multirow[t]{2}{*}{ Model } & \multirow[t]{2}{*}{ Parameter } & \multicolumn{3}{|c|}{ Temperature $\left({ }^{\circ} \mathrm{C}\right)$} \\
\hline & & 30 & 40 & 50 \\
\hline \multirow{3}{*}{ Langmuir } & $\mathbf{q}_{\mathrm{m}, \mathrm{cal}}(\mathrm{mg} / \mathrm{g})$ & 1.744 & 2.481 & 3.416 \\
\hline & $K_{L}(L / m g)$ & 0.764 & 0.353 & 0.218 \\
\hline & $\mathbf{R}^{2}$ & 0.926 & 0.896 & 0.923 \\
\hline \multirow{3}{*}{ Freundlich } & $\mathbf{K}_{\mathrm{F}}(\mathbf{m g} / \mathrm{g})$ & 0.804 & 0.749 & 0.734 \\
\hline & $\mathbf{n}$ & 3.254 & 2.293 & 2.001 \\
\hline & $\mathbf{R}^{2}$ & 0.502 & 0.672 & 0.856 \\
\hline \multirow{3}{*}{ Temkin } & $B$ & 0.871 & 0.635 & 0.385 \\
\hline & $K_{T}(L / g)$ & 1.563 & 1.423 & 1.331 \\
\hline & $\mathbf{R}^{2}$ & 0.424 & 0.631 & 0.878 \\
\hline \multirow{4}{*}{$\begin{array}{c}\text { Dubinin- } \\
\text { Radushkevich }\end{array}$} & $\mathbf{q}_{\mathbf{m}, \text { cal }}(\mathbf{m g} / \mathbf{g})$ & 1.798 & 2.222 & 2.554 \\
\hline & $K_{D R}\left(\mathrm{~mol}^{2} / \mathrm{KJ}^{2}\right)$ & 1.056 & 1.212 & 1.125 \\
\hline & $\mathrm{E}(\mathrm{KJ} / \mathbf{m o l})$ & 0.688 & 0.642 & 0.668 \\
\hline & $\mathbf{R}^{2}$ & 0.774 & 0.899 & 0.987 \\
\hline
\end{tabular}


Table 9. Calculated values for constant $\mathrm{R}_{\mathrm{L}}$ at different temperatures and MB initial concentrations.

\section{MB Initial concentration (mg/L)}

\begin{tabular}{cccc}
\hline & $\mathbf{5}$ & $\mathbf{1 0}$ & $\mathbf{1 5}$ \\
\hline Temperature $\left({ }^{\circ} \mathbf{C}\right)$ & & & 0.08 \\
\hline $\mathbf{3 0}$ & 0.20 & 0.11 & 0.16 \\
\hline $\mathbf{4 0}$ & 0.36 & 0.22 & 0.24 \\
\hline
\end{tabular}




\section{Figures Captions}

Fig. 1. UV-vis absorbance spectra of $\mathrm{MB}$ dye solution at various concentrations (a) $\mathrm{pH}=4$, (b) $\mathrm{pH}=7$ and (c) $\mathrm{pH}=9$.

Fig. 2. The $\mathrm{MB}$ standard calibration curves at (a) $\mathrm{pH}=4$, (b) $\mathrm{pH}=7$ and (c) $\mathrm{pH}=9$.

Fig. 3. XRD patterns of pristine MMT clay and HA0 and HA8 adsorbents.

Fig. 4. FESEM images of the fracture surfaces of the (a) HAO and (b) HA8 adsorbents.

Fig. 5. BET isotherms for HA0 and HA8 adsorbents at $77 \mathrm{~K}$.

Fig. 6. Gel content values of the prepared BHAs.

Fig. 7. Swelling kinetic curves of the BHAs at (a) $\mathrm{pH}=4$, (b) $\mathrm{pH}=7$ and (c) $\mathrm{pH}=9$.

Fig. 8. Equilibrium swelling ratios of BHAs versus the MMT content and the $\mathrm{pH}$ of the swelling medium.

Fig. 9. $\mathrm{MB}$ concentration curves versus time in the receptor and donor compartments at $37{ }^{\circ} \mathrm{C}$ and $\mathrm{pH}$ of (a and b) 4, (c and d) 7 and (e and f) 9.

Fig. 10. $-\ln (\mathrm{x})$ curves versus time for $\mathrm{BHAs}$ at (a) $\mathrm{pH}=4$, (b) $\mathrm{pH}=7$ and (c) $\mathrm{pH}=9$.

Fig. 11. The effects of the $\mathrm{pH}$ of adsorption solution, MMT loading level in BHA and MB initial concentration in adsorption solution on $\mathrm{S} / \mathrm{N}$ ratios.

Fig. 12. Comparison of experimental data with pseudo-first-order, pseudo-second-order, Elovich and intra-particle diffusion kinetic models at MB initial concentrations of (a) 5, (b) 10 and (c) 15 mg/L .

Fig. 13. Comparison of experimental data with Langmuir, Freundlich, Temkin and DubininRadushkevich isotherm models at (a) 30, (b) 40 and (c) $50{ }^{\circ} \mathrm{C}$.

Fig. 14. MB desorption curves for BHAs in $0.04 \mathrm{M}$ acetic acid solution. 


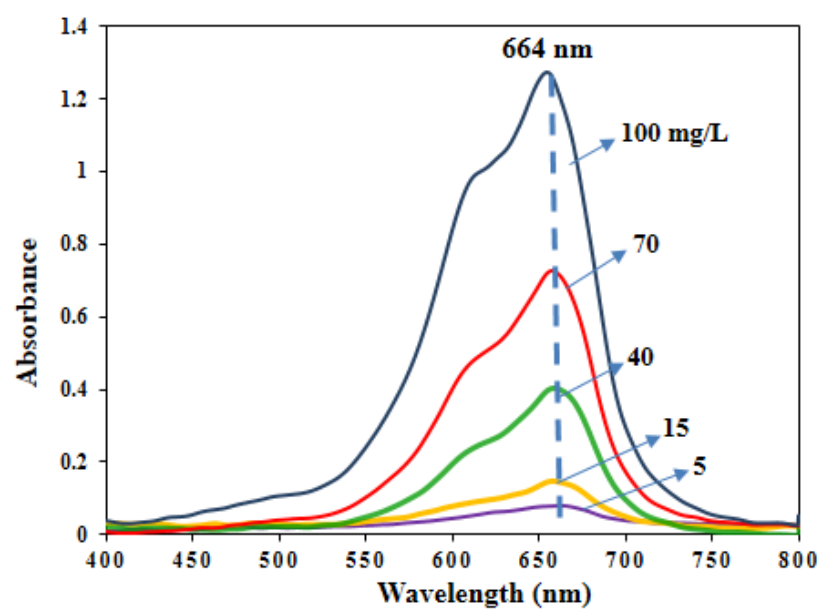

(a)

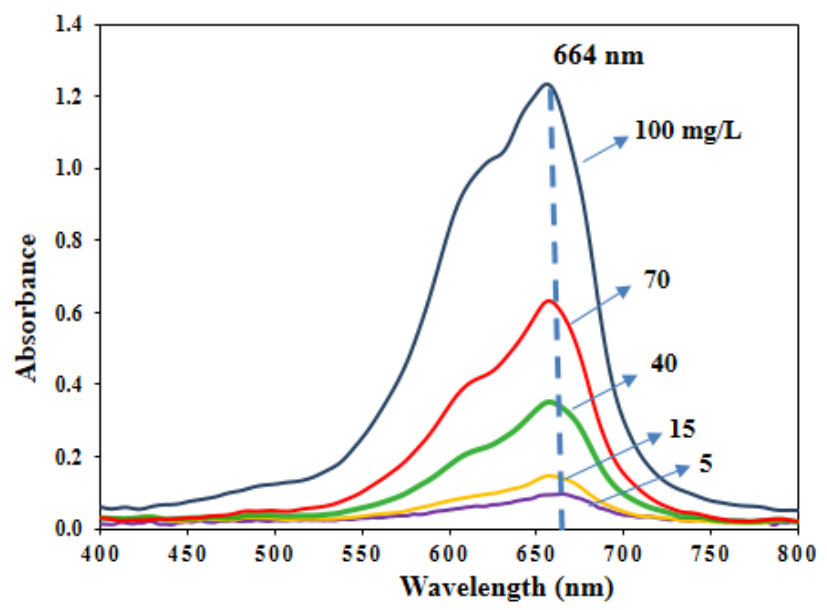

(b)

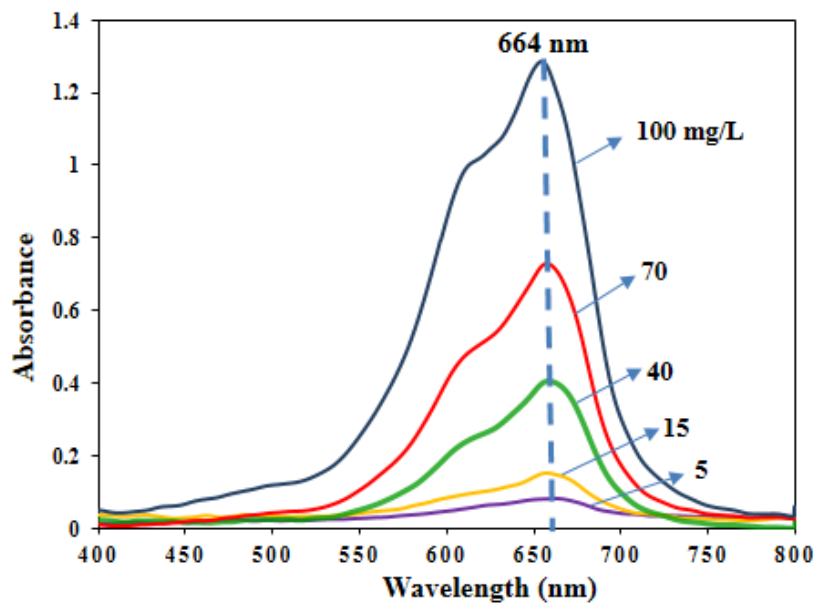

(c)

Fig. 1. UV-vis absorbance spectra of $\mathrm{MB}$ dye solution at various concentrations (a) $\mathrm{pH}=4$, (b) $\mathrm{pH}=7$ and (c) $\mathrm{pH}=9$. 


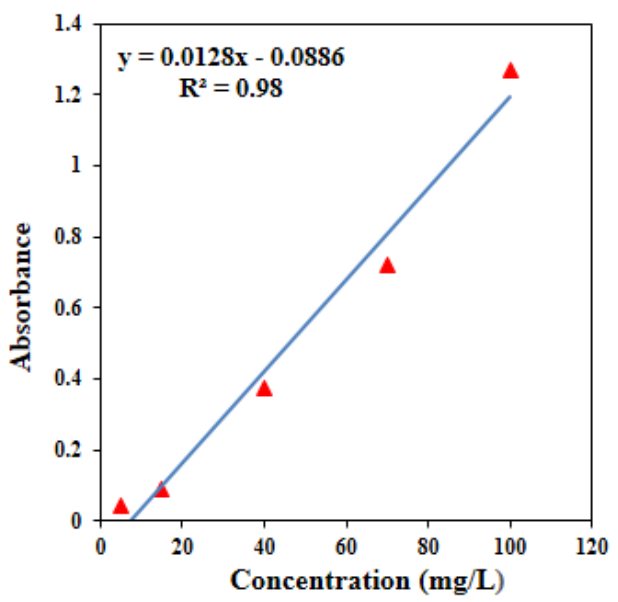

(a)

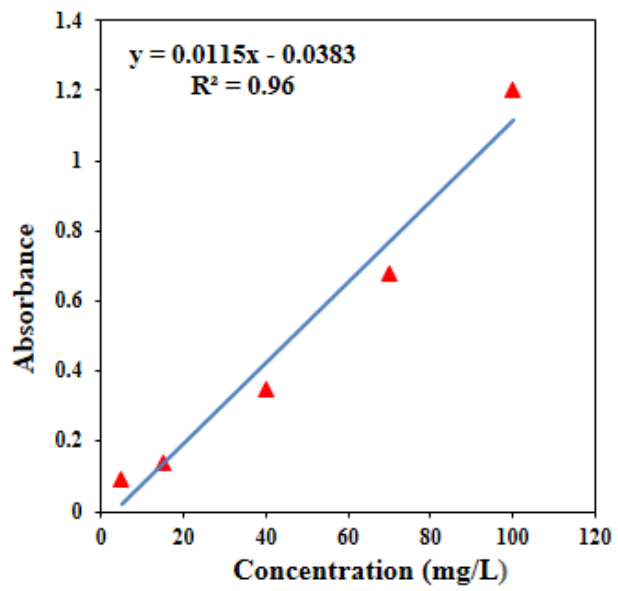

(b)

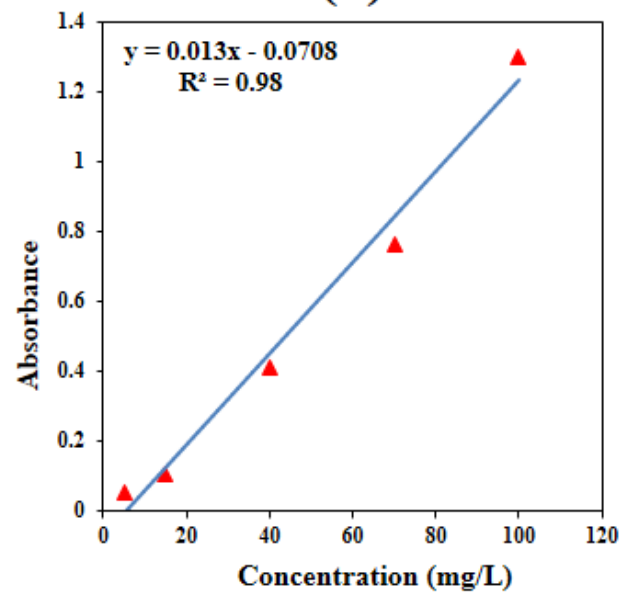

(c)

Fig. 2. The MB standard calibration curves at (a) $\mathrm{pH}=4$, (b) $\mathrm{pH}=7$ and (c) $\mathrm{pH}=9$. 


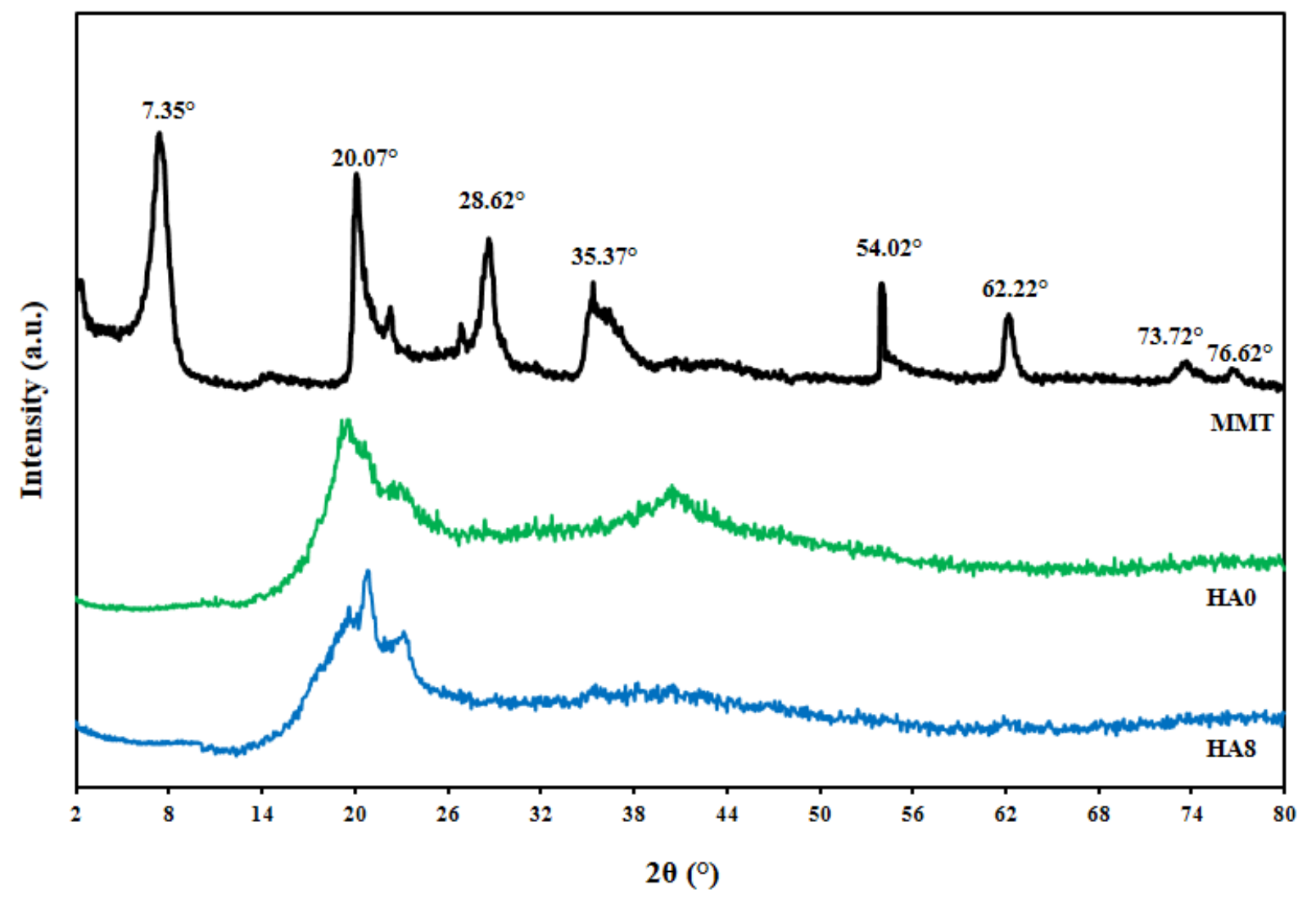

Fig. 3. XRD patterns of pristine MMT clay and HA0 and HA8 adsorbents. 


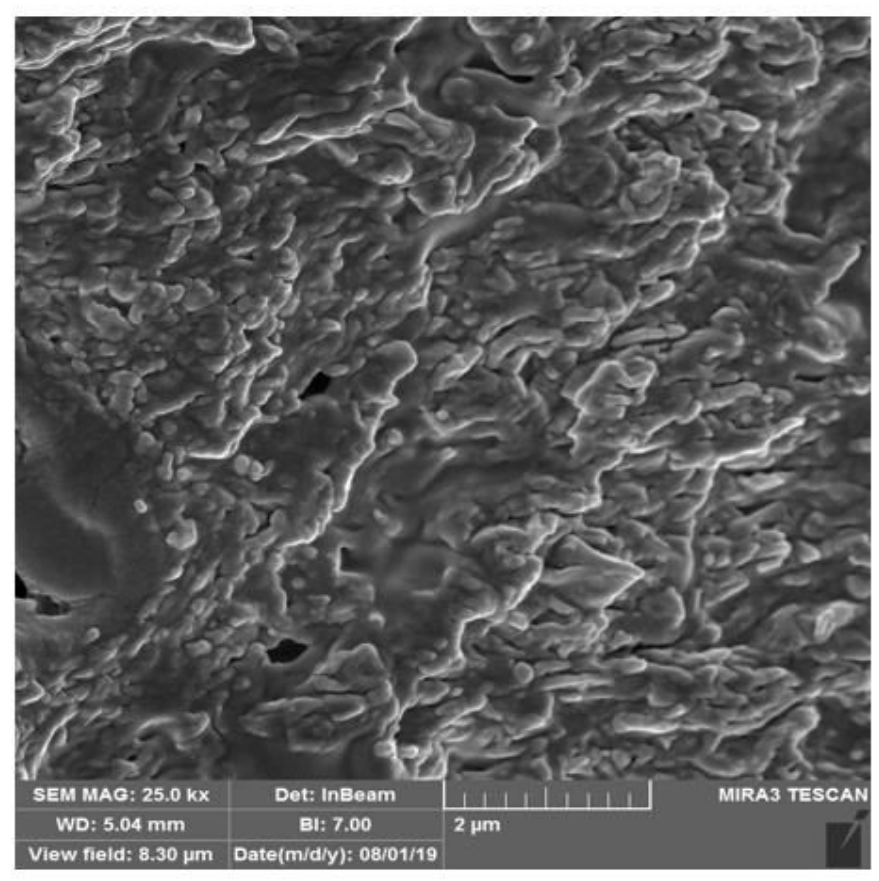

(a)

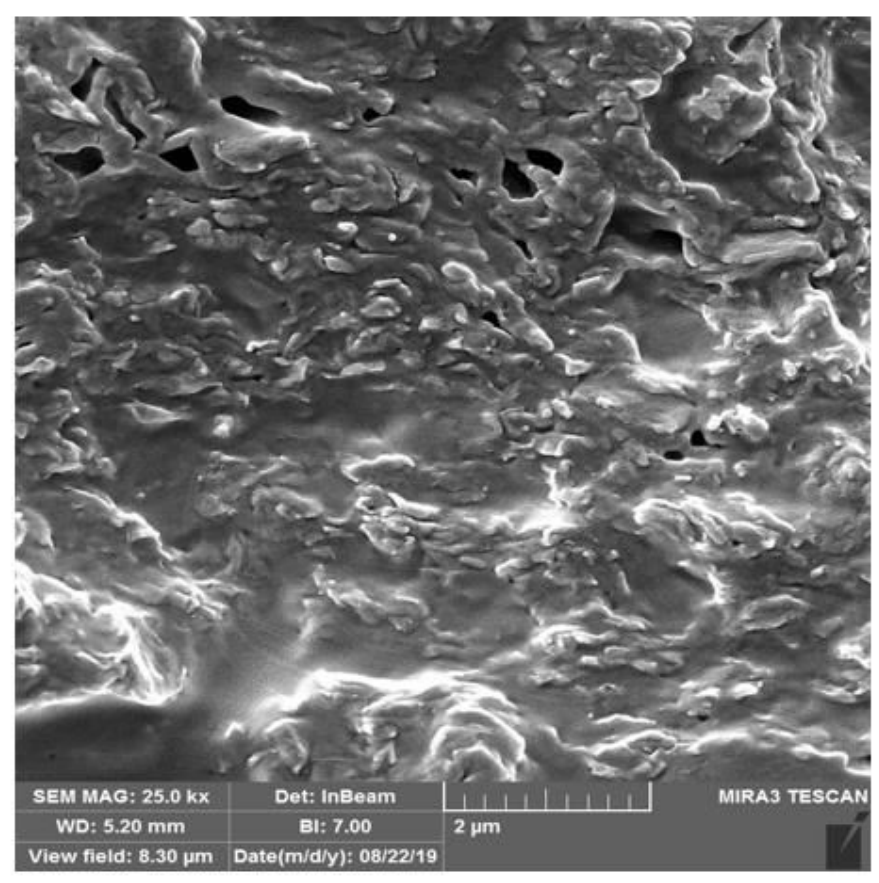

(b)

Fig. 4. FESEM images of the fracture surfaces of the (a) HAO and (b) HA8 adsorbents. 


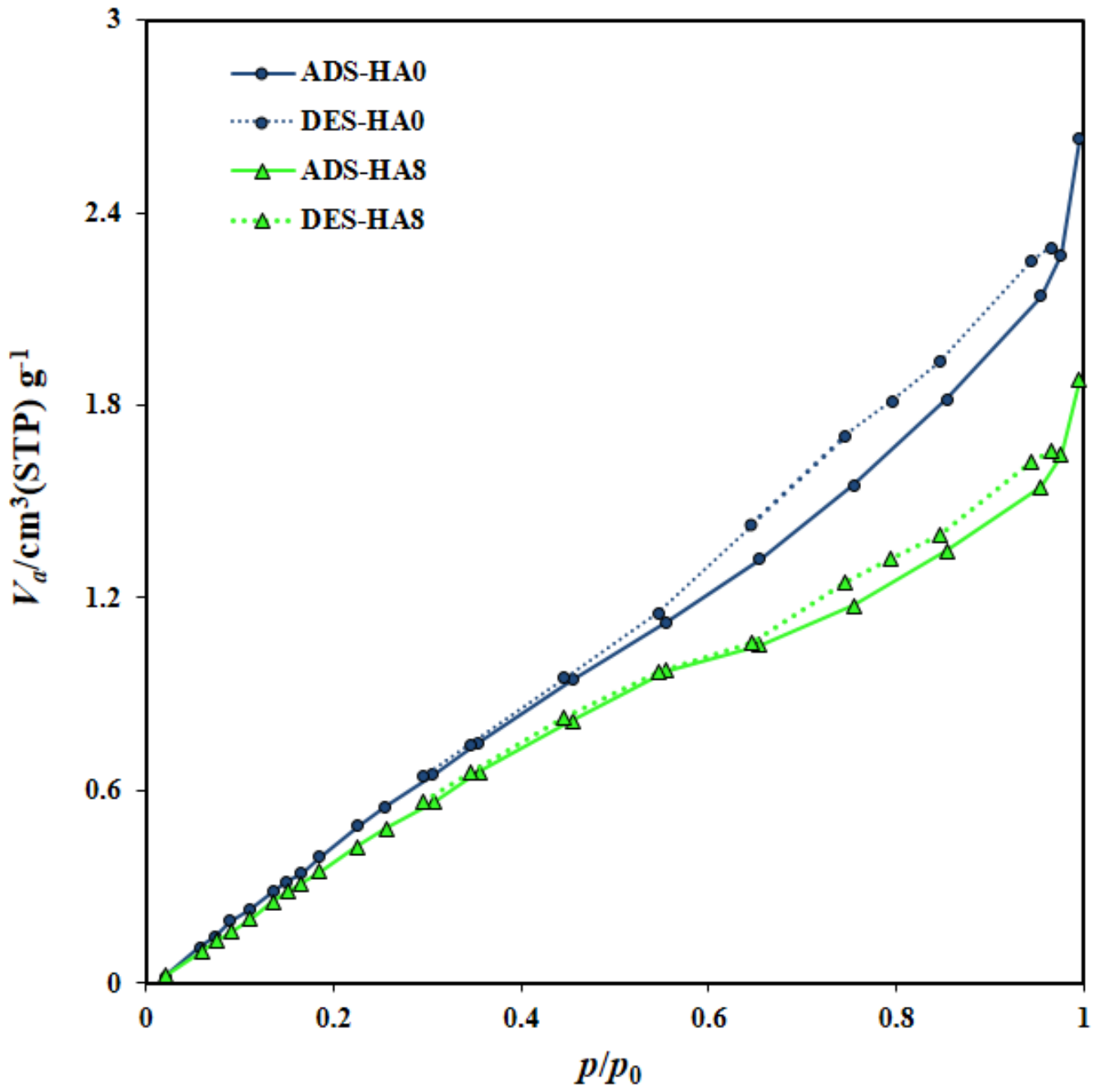

Fig. 5. BET isotherms for HA0 and HA8 adsorbents at $77 \mathrm{~K}$. 


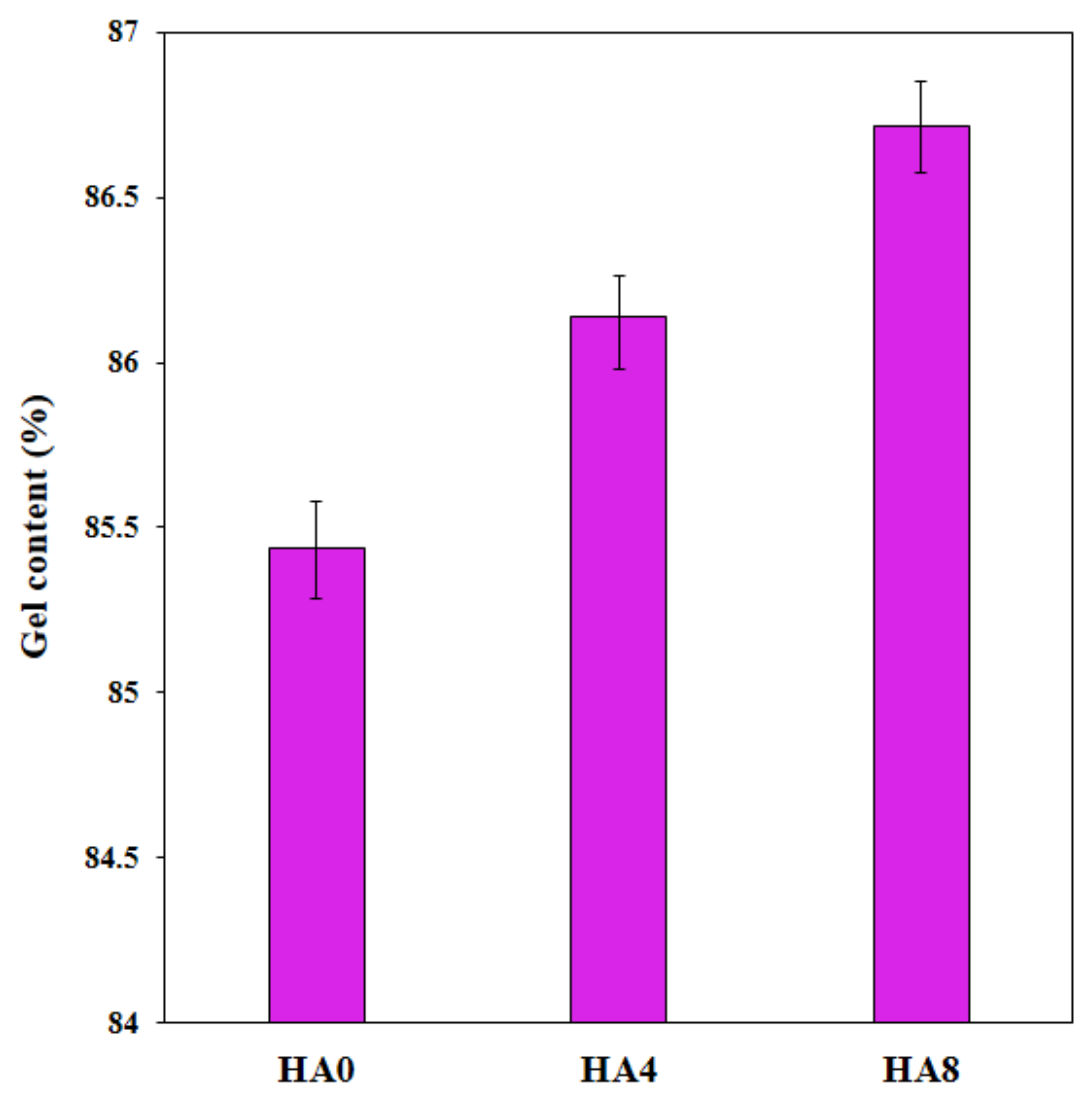

Fig. 6. Gel content values of the prepared BHAs. 


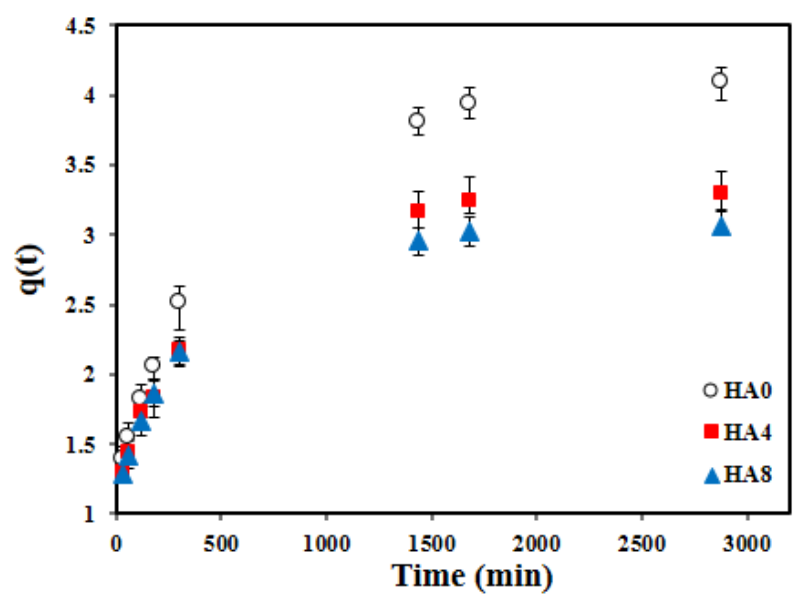

(a)

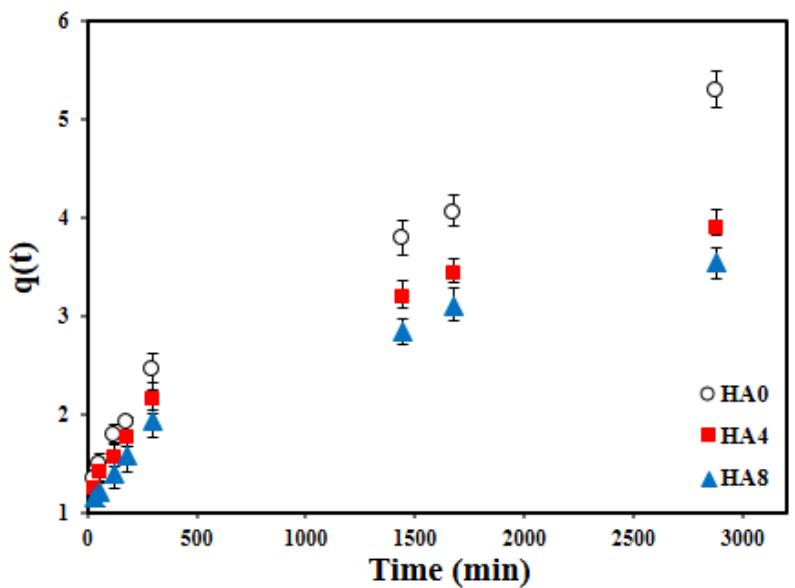

(b)

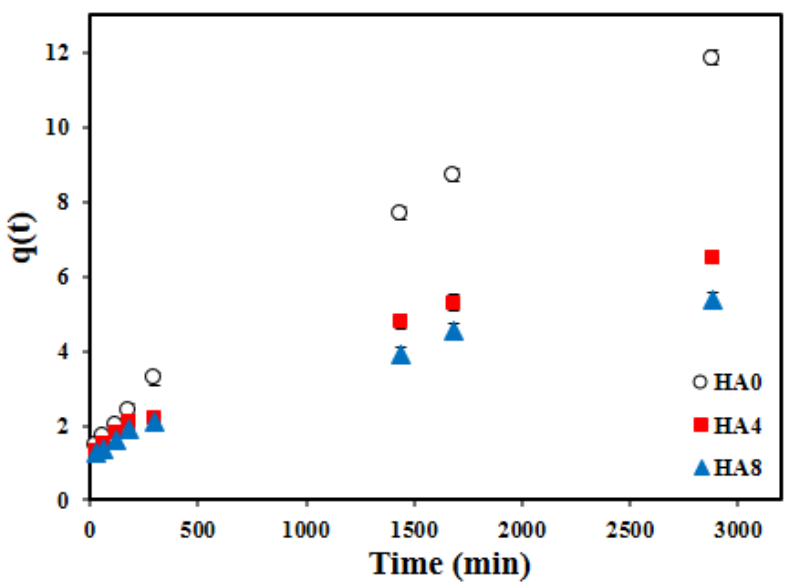

(c)

Fig. 7. Swelling kinetic curves of the BHAs at (a) $\mathrm{pH}=4$, (b) $\mathrm{pH}=7$ and (c) $\mathrm{pH}=9$. 


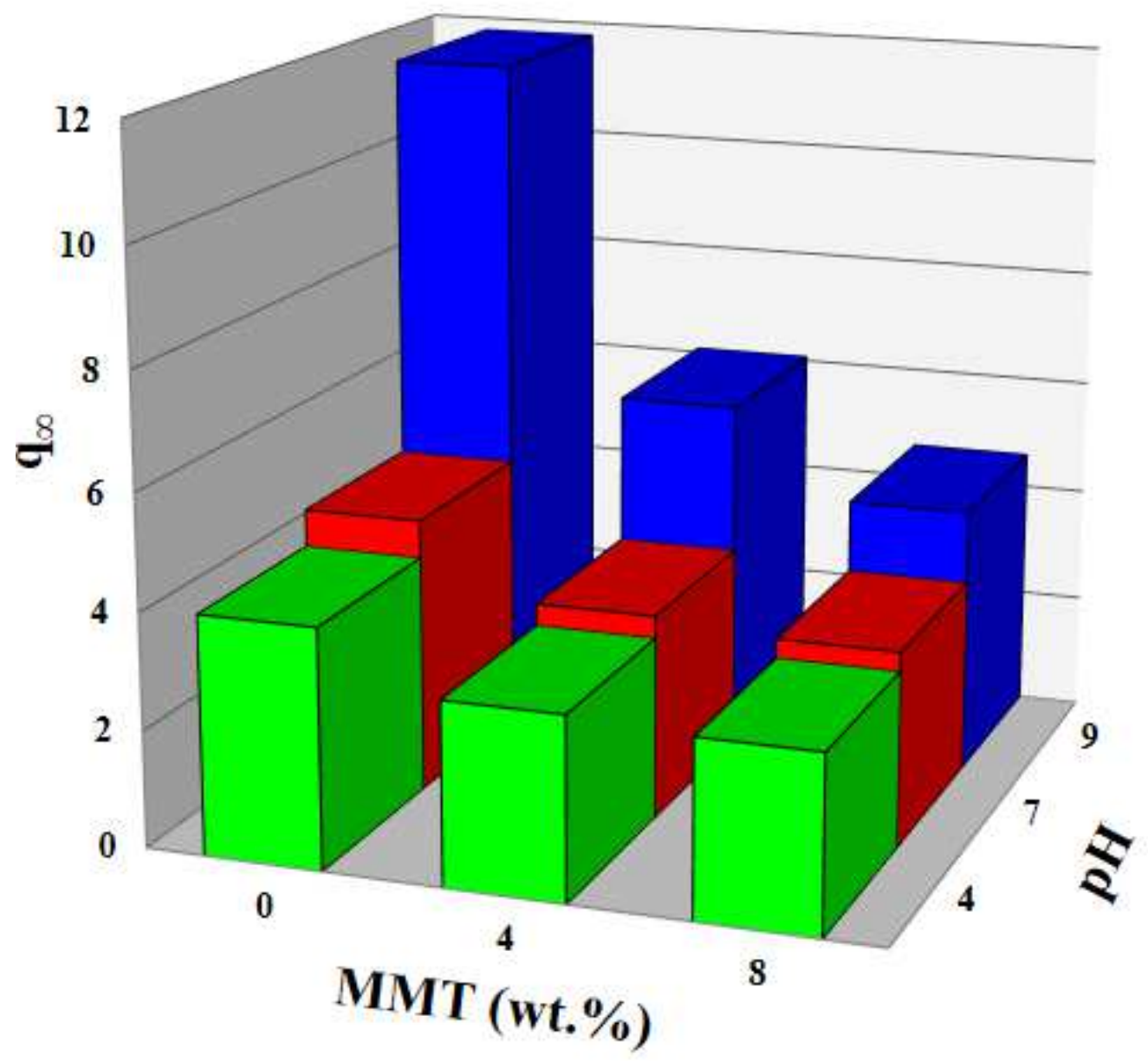

Fig. 8. Equilibrium swelling ratios of BHAs versus the MMT content and the $\mathrm{pH}$ of the swelling medium. 


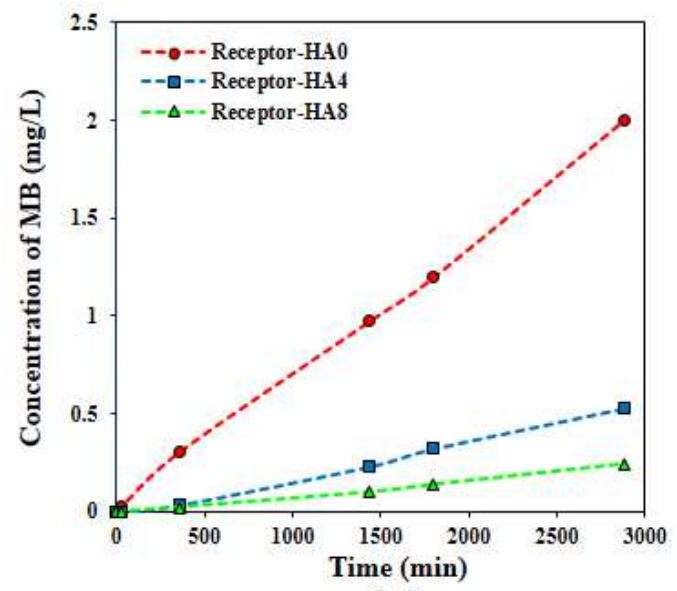

(a)

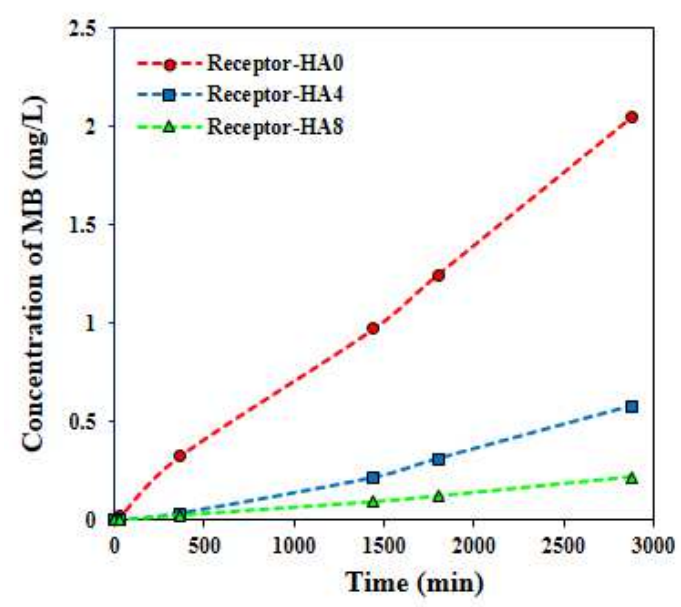

(c)

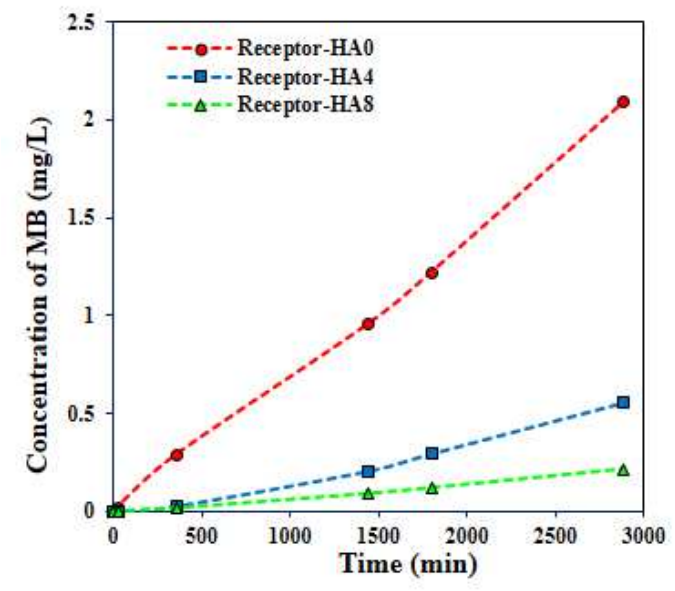

(e)

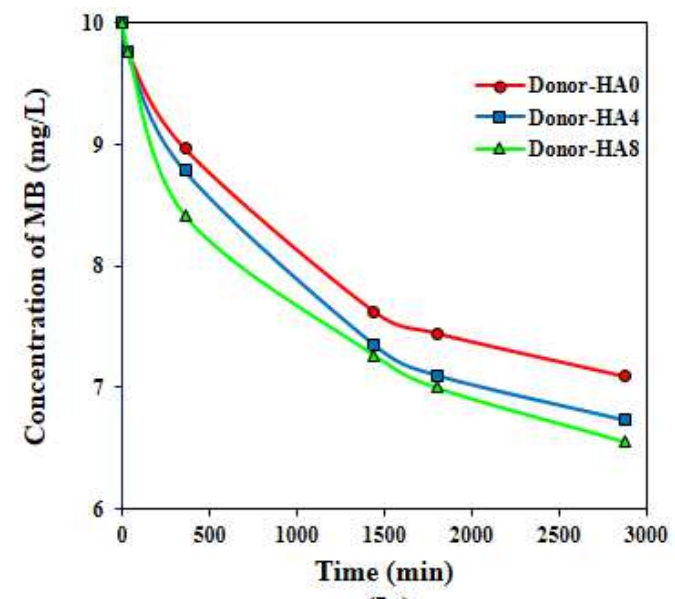

(b)

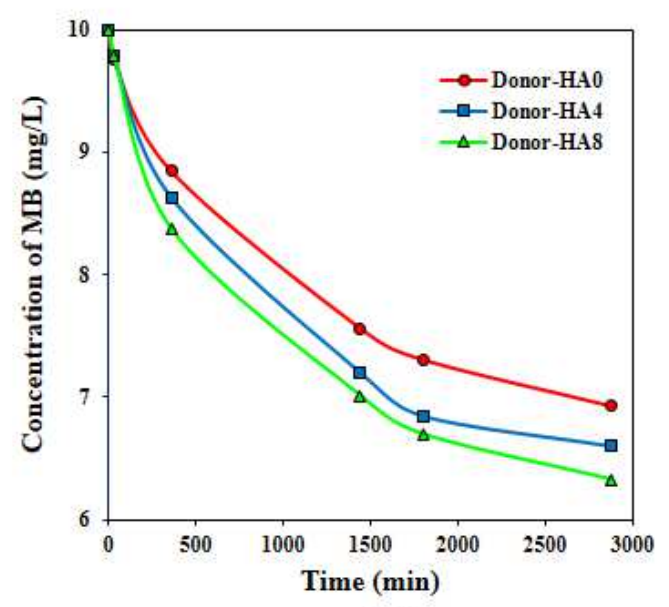

(d)

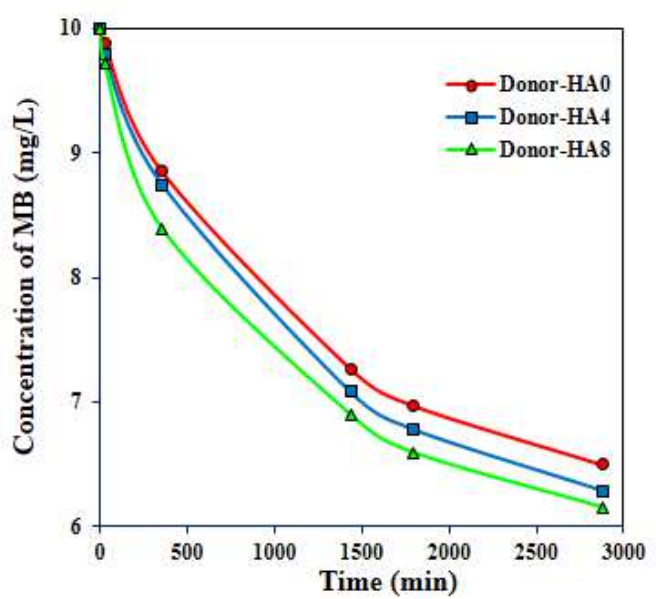

(f)

Fig. 9. $\mathrm{MB}$ concentration curves versus time in the receptor and donor compartments at $37{ }^{\circ} \mathrm{C}$ and $\mathrm{pH}$ of (a and b) 4, (c and d) 7 and (e and f) 9 . 


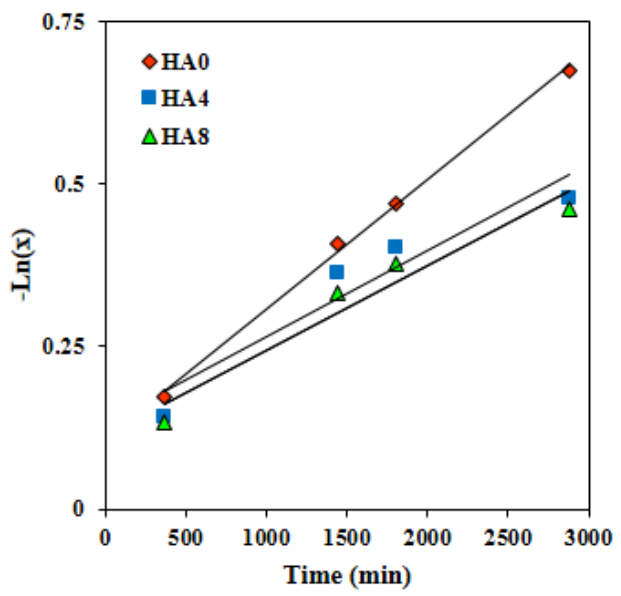

(a)

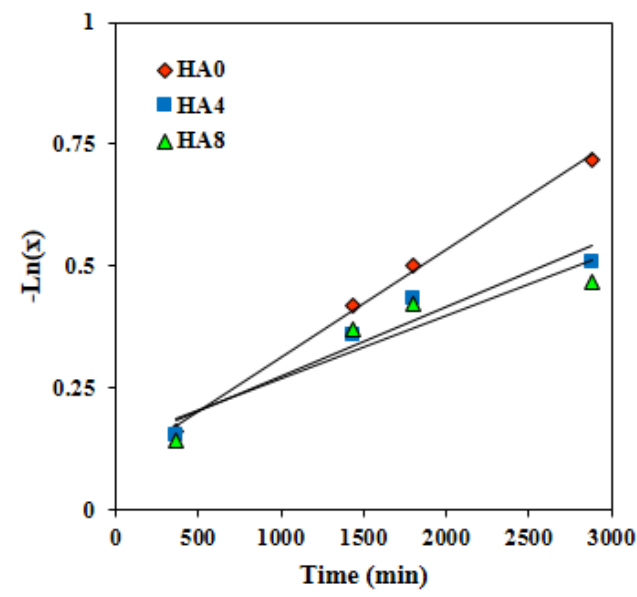

(b)

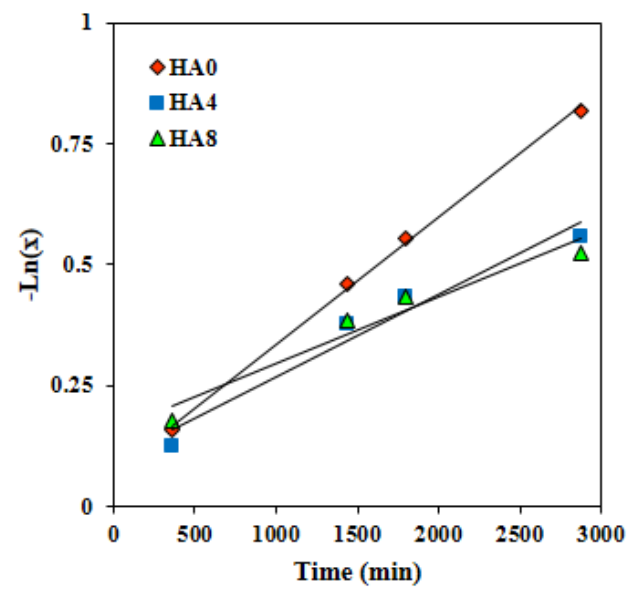

(c)

Fig. 10. $-\ln (\mathrm{x})$ curves versus time for $\mathrm{BHAs}$ at (a) $\mathrm{pH}=4$, (b) $\mathrm{pH}=7$ and (c) $\mathrm{pH}=9$. 


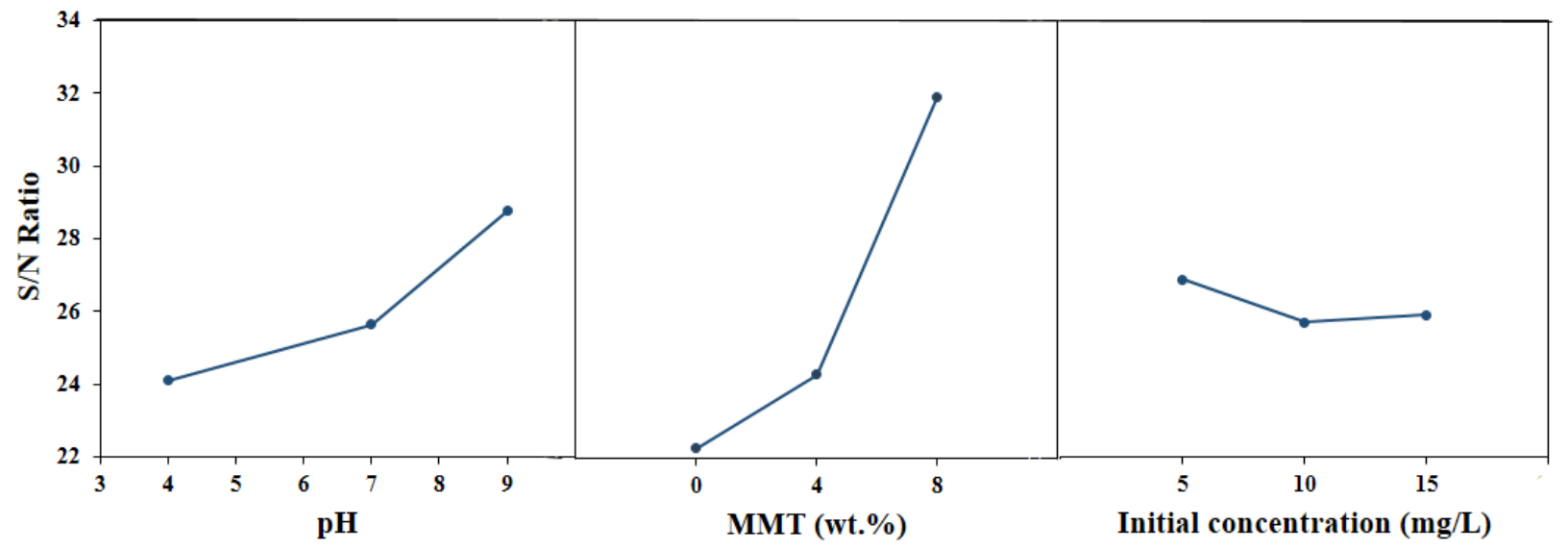

Fig. 11. The effects of the $\mathrm{pH}$ of adsorption solution, MMT loading level in BHA and MB initial concentration in adsorption solution on $\mathrm{S} / \mathrm{N}$ ratios. 


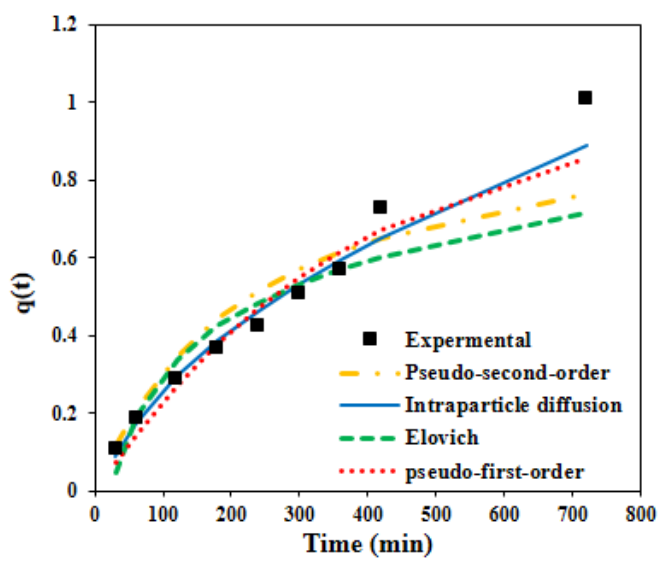

(a)

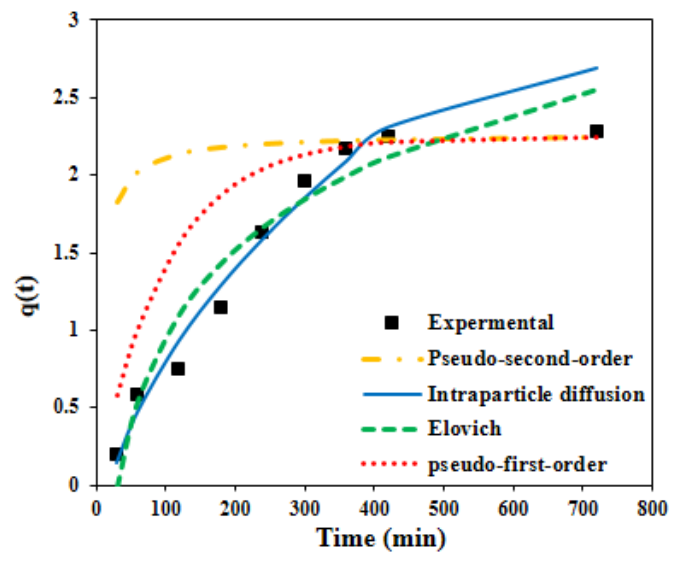

(b)

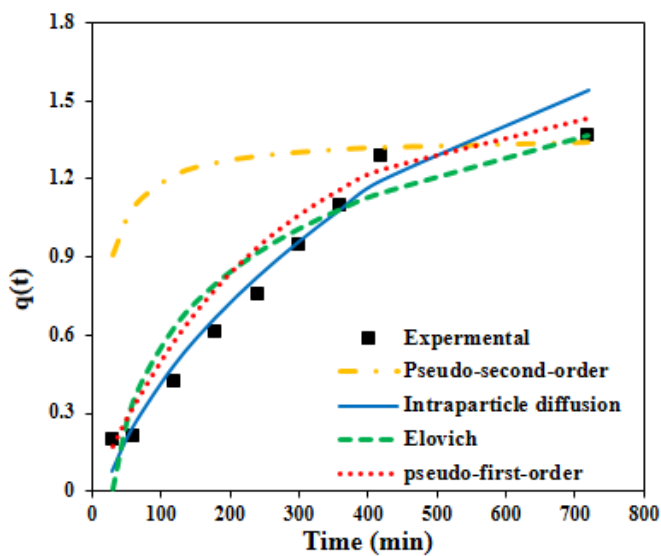

(c)

Fig. 12. Comparison of experimental data with pseudo-first-order, pseudo-second-order, Elovich and intra-particle diffusion kinetic models at MB initial concentrations of (a) 5, (b) 10 and (c) 15 $\mathrm{mg} / \mathrm{L}$. 


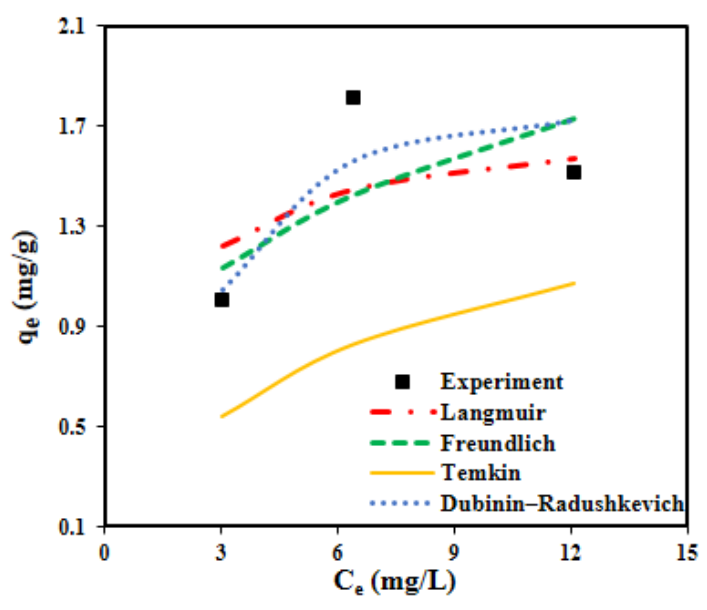

(a)

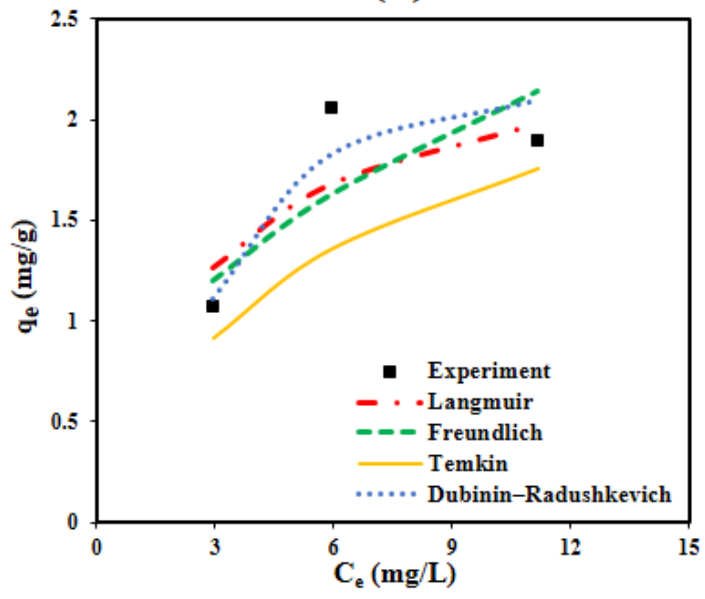

(b)

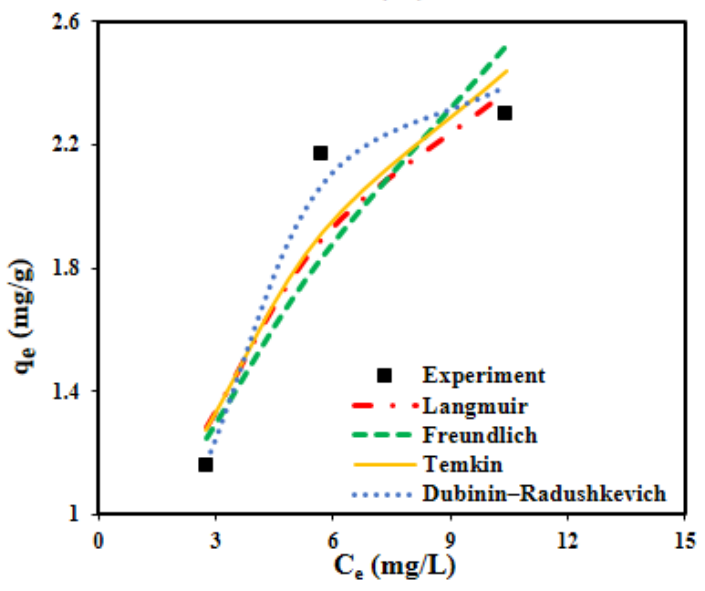

(c)

Fig. 13. Comparison of experimental data with Langmuir, Freundlich, Temkin and DubininRadushkevich isotherm models at (a) 30 , (b) 40 and (c) $50{ }^{\circ} \mathrm{C}$. 


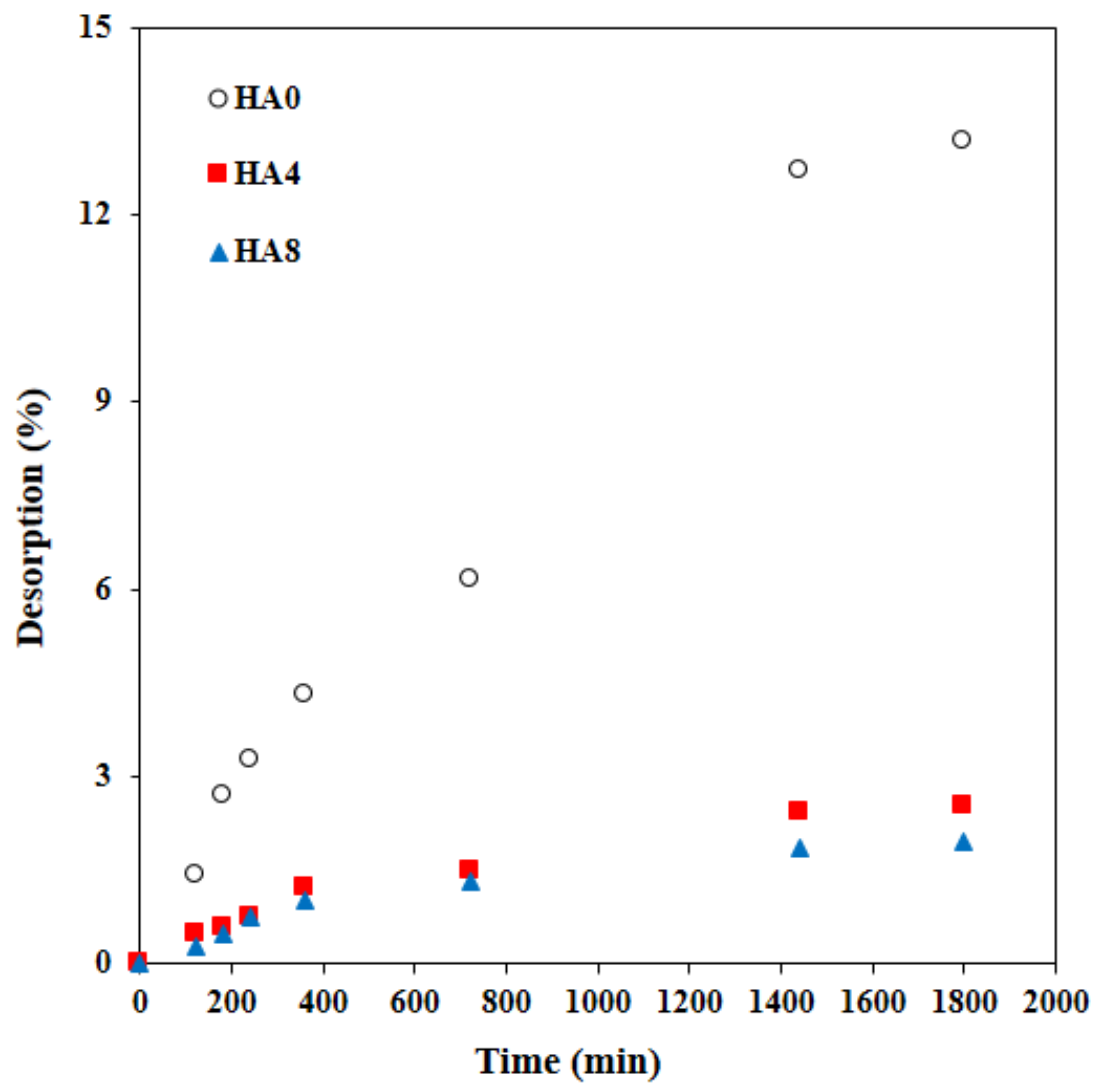

Fig. 14. MB desorption curves for BHAs in $0.04 \mathrm{M}$ acetic acid solution. 